\title{
V. Die Neugliederungsdiskussion in den politischen Parteien
}

Die Neugliederungsdiskussion der unmittelbaren Nachkriegszeit war nicht nur in den sich ab Ende 1945 formierenden politischen Parteien intensiv betrieben worden. Auch aus den Konzepten selbst erwuchsen organisatorische Entwürfe für Parteigründungen, die jedoch entweder über das Planungsstadium nicht hinauskamen oder aber von der französischen Besatzungsmacht nicht lizenziert wurden. Darüber hinaus zeigt sich, daß mit Ausnahme der Kommunisten keine politische Partei frei von Flügeln war, die sich für eine weitgehende Autonomie und die direkte Einbindung des deutschen Südwestens in eine europäische Konföderation einsetzten. Die Bildung des Landes Rheinland-Pfalz im Sommer 1946 erachteten die meisten führenden Politiker im Südteil der Französischen Besatzungszone (FBZ) als „das Vorspiel zur Errichtung eines neuen Staates Südbaden-Südwürttemberg, dessen Hauptstadt Freiburg sein würde“1. Eine Auseinandersetzung mit den Postulaten des "Schwäbisch-Alemannischen Heimatbundes“ und dem Inhalt von Otto Fegers Buch war deshalb unausweichlich; letztlich konnte aber die Forderung nach weitgehender Autonomie in keiner der südwestdeutschen Parteien Oberhand gewinnen. Der einzige Versuch der Gründung einer autonomistischen Partei scheiterte an der Ablehnung durch die französische Besatzungsmacht. Auch andere politische Planungen blieben nicht mehr als Projekte, sie zeigen aber deutlich, daß föderalistischautonomistische Positionen nach 1945 im Südwesten allgegenwärtig waren.

\section{Das lizenzierte Parteienspektrum}

Erste Tendenzen zur Gründung von politischen Parteien in der FBZ datieren auf den Spätsommer 1945 zurück. Die Auflage der Besatzungsmacht, zuerst die Landes- und danach die Kreis- und Ortsverbände zu gründen, erleichterte den Aufbau der Parteien keinesfalls und bewirkte, daß die Parteigründungen nicht vor Jahresbeginn 1946 vollzogen werden konnten. Welchen Einfluß die Neugliederungskonzepte auf die sich formierenden politischen Parteien des Südwestens hatten, ist ein bisher in der Erforschung der Parteiengeschichte vernachlässigter Aspekt. Föderalistische Positionen und Autonomievorstellungen sind freilich in allen Parteien - bis auf die Kommunisten - in wahrnehmbarem Umfang propagiert worden.

\section{Die BCSV/CDU in Baden}

Die Badisch-Christlich Soziale Volkspartei ${ }^{2}$ (BCSV) war in Freiburg aus zwei rivalisierenden Gruppen - der Zentrumsgruppe ${ }^{3}$ und der Christlichen Arbeitsgemeinschaft hervorgegangen. Die formelle Parteigründung samt Wahl des vorläufigen Vorsitzenden

\footnotetext{
${ }^{1}$ Bade, Rapport mensuel, Août 1946; AdO Bade Cabinet c. 1104/1.

2 Vgl. dazu Fäßler, Geschichte, 1995.
} 
Leo Wohleb datiert auf den 20. Dezember 19454. Der Leiter der Hochschulabteilung war im Sommer 1945 im Gefolge der französischen Militärregierung von Karlsruhe nach Freiburg gekommen und galt als Kompromißkandidat. Nach einigen formalen Verzögerungen erhielt die BCSV, am 6. Februar 1946 die Zulassung durch die französische Militärregierung. Im historischen Kaufhaussaal am Freiburger Münsterplatz, dem späteren Landtagsgebäude, fand am 24. Februar der Gründungsparteitag statt. Die Konfrontation zwischen den CDU/CSU-Gruppierungen aus dem Raum Konstanz und den Freiburger CSV/BCSV-Gruppen blieb nicht aus, man entschied sich letztlich für die „heimattreue“, badische Lösung.

Im Seekreis reichten die Ursprünge einer christlichen Parteigründung ebenfalls in den Dezember 1945 zurück. Zeitgleich mit dem Reichstreffen der CDU in Bad Godesberg konstituierte sich am 14. und 15. Dezember in Hegne am Bodensee ein gewerkschaftlicher Arbeitsausschuß, die sogenannte "Christlich-Soziale Vereinigung"s. Es handelte sich um ein Treffen ehemaliger christlicher Gewerkschaftler, die aus den französisch besetzten Teilen Badens und Württembergs angereist waren. In der kleinen Bodenseegemeinde vertrat der Volksschullehrer Hugo Wilhelm Mayer ${ }^{6}$ eine entschiedene Demokratisierung des Bildungswesens; er war am Zustandekommen der Konferenz maßgeblich beteiligt. Die Hauptreferate übernahmen Karl Gengler ${ }^{7}$ und Hermann Henseler; die Beschlüsse der "Christlich-Sozialen Vereinigung " wurden in einer zehnseitigen Broschüre gedruckt, in der die Rede war von einem „christlichen Ständestaat, verwirklicht im deutschen Rätebund, bestehend aus freien Arbeiter- und Bauernrepubliken" ${ }^{\text {". Das }}$ gedruckte Programm, das Makulatur blieb, machte auf Wilhelm Hugo Mayer starken Eindruck. Hatte er doch bereits im März 1945 in einem Schreiben an Erzbischof Gröber den Vorschlag der Gründung eines "Christlichen Friedensringes" gemacht", einer pazifistisch-christlichen Laienorganisation. Im Juni 1945 übermittelte er Gröber einen Programmentwurf des „Friedensringes aller Christen in Deutschland" 10 , der jedoch außer

${ }^{3}$ In der Zentrumsgruppe war 1945 neben Ernst Föhr, Wolfgang Hoffmann und Paul Zürcher auch Josef Ruby, der Gründer der „Vereinigung Abendland“, aktiv; Wieck, Demokraten, S. 105.

4 Weinacht/Mayer, Ursprung, S. 39.

${ }^{5}$ Ebenda, S. 48.

${ }^{6}$ Hugo Wilhelm Mayer (1890-1969), 1910 Mitglied der „Marianischen Kongregation"; um 1920 Gründer einer christlichen Gewerkschaft in Wutöschingen; Präsident und Laienprediger der "Pax-Christi-Bewegung“; 1923 Volksschullehrer in Günterstal (Freiburg); enge Kontakte zum. badischen Zentrumsführers Prälat Josef Schofer; 1933 aus politischen Gründen (Zentrumsmitgliedschaft) als Volksschullehrer nach Hegne/Bodensee versetzt; 1954 Gründer des „Verbands der Katholischen Lehrerschaft Deutschlands“; nach der Pensionierung Altersruhesitz in Freiburg. Von seinem Sohn verfaßte, bis 1934 reichende Biographie: Mayer, Patriot.

${ }^{7}$ Karl Gengler (1886-1974), Klempnerlehre; 1910 Gewerkschaftsangestellter; 1919 Vorsitzender des Landeskartells der Christlichen Gewerkschaften; 1919-33 MdL Württemberg (Zentrum); 1945 Geschäftsführer der AOK Rottweil, Vorstandsmitglied des Gewerkschaftsbundes Südwürttemberg-Hohenzollern; 1946-56 im Landesvorstand der CDU; 1946 Präsident der Beratenden Landesversammlung Württemberg-Hohenzollern; 1947-52 Präsident des Landtages Württemberg-Hohenzollern; 1948-49 Präsident des Landesarbeitsamtes; 1949-57 MdB (CDU); 194760 Vorsitzender der CDA Südwürttemberg. Vgl. Weinacht, CDU, S. 346.

${ }^{8}$ Weinacht/Mayer, Ursprung, S. 49.

${ }^{9}$ Wilhelm Hugo Mayer: Christlicher Friedensring (masch. 20 S.); Mayer an Gröber vom 19. 3. 1945; EAF NL Gröber Nb 8/62.

10 "Friedensring aller Christen in Deutschland. Programm“ (masch. 2 S.); Mayer an Gröber vom 6. 6. 1945; EAF NL Gröber Nb 8/52. 
der Definition des Staates als „gottgewollte, natürliche und völkischnationale Lebensform" keine näheren Ausführungen zur politischen Gliederung Deutschlands enthielt. Mit Hinweis auf die stattfindende Gewerkschafterversammlung der „Christlich Sozialen Vereinigung " betonte Mayer, daß viele Teilnehmer den Friedensring erwarteten ${ }^{11}$. Letztlich zog aber der Volksschullehrer das Projekt des Friedensringes zurück, da ihm als ehemaligem Parteigenossen - er war während des Zweiten Weltkrieges in Konstanz für den Luftschutz im Landkreis zuständig gewesen - die Vereinsgenehmigung von seiten der französischen Besatzungsmacht nicht erteilt worden wäre. Oberst Sprauer von der Freiburger Oberdelegation wollte Mayer und dessen Plänen eine Wendung im föderalistischen Sinn geben: „Ich habe erkannt," schrieb Mayer im März 1946 nach Freiburg an Erzbischof Gröber, „dass das Verhalten des Herrn Obersten Sprauer ${ }^{12}$ vom Militairgouvernement in Fbg, der mich unbedingt mit Herrn Dr. Dietrich, Singen verkoppeln wollte, eine bedenkliche Seite hat, weil ich der Meinung bin, dass das ,Alpenland' des Herrn D. eine separatistische Tendenz in sich trägt und damit dem, was der Christliche Friedensring will, zuwiderläuft. Auch habe ich das Gefühl, dass auch das ,Abendland ${ }^{13}$ unter separatistischen Einfluss genommen werden kann." ${ }^{14}$ Die nationale Gesinnung Wilhelm Hugo Mayers trat deutlich ans Licht; mit ihr war er bei einem Mann vom Schlage eines Conrad Gröber an der richtigen Stelle.

Der ebenfalls vaterländische Akzent der Konstanzer CSU-Gruppe unter Vorsitz des dortigen Oberbürgermeisters Franz Knapp wird in der Forschung als Reaktion "gegen separatistische Tendenzen im Seekreis" ${ }^{15}$ analysiert. Zu bedenken bleibt aber die Tatsache, daß Bernhard Dietrich trotz seiner allgemein bekannten Alpenlandpropaganda auf der Gründungsversammlung des BCSV-Ortsverbandes Singen das Gründungsreferat hielt und im September 1946 als BCSV-Mitglied in den dortigen Stadtrat einzog. Seine Wahl zum Bürgermeister wurde im Herbst 1946 nicht wegen seiner "separatistischen“ Pläne vereitelt, sondern weil von demokratischer Seite nur ein in religiöser Hinsicht unvoreingenommener BCSV-Kandidat die nötige Unterstützung finden konnte. Die Wahl fiel auf Theopont Diez ${ }^{16}$, den Sohn des in Freiburg für Ernährung und Landwirtschaft zuständigen ehemaligen Reichstagsabgeordneten Carl Diez. Der Machtwechsel im Singener Rathaus ist ausschließlich auf das Verhalten der Demokraten zurückzuführen. Wollte sich die BCSV wirklich klar gegen den "Separatismus" abgrenzen, hätte Bernhard Dietrich nie in die Partei aufgenommen werden, geschweige denn als Mandatsträ-

\footnotetext{
11 Mayer an Gröber vom 2. 12. 1945; EAF NL Gröber Nb 8/60.

12 Oberst Sprauer verkehrte regelmäßig bei Josef Ruby, dem Freund Dietrichs und Gründer der „Vereinigung Abendland“ in Freiburg; Interview mit Rudolf Ruby am 7.6. 1994; StadtA KN Cc 775 a.

${ }^{13}$ Zur „Vereinigung Abendland“ vgl. Kapitel II/1.

${ }^{14}$ Mayer an Gröber vom 19. 3. 1946; EAF NL Gröber Nb 8/60.

15 Weinacht/Mayer, Ursprung, S. 51. Dieselbe Ansicht vertritt Fäßler, Neubeginn, S. 388. Beide Einschätzungen dürften auf Wieck, Demokraten, S. 119 f. fußen.

16 Theopont Diez (1908-1993), 1927 Abitur an der Oberrealschule in Konstanz; Studium der Rechtswissenschaften in Freiburg/Schweiz, Berlin, München und Heidelberg; 1931 Referendarprüfung in Karlsruhe; Mitglied des Zentrums und im Windthorstbund; 1934 Rechtsanwalt in Singen; 1940-45 Kriegsdienst; 1946 Mitglied der BCSV und Wahl zum Bürgermeister von Singen (1946-69); 1952-72 MdL Baden-Württemberg (CDU); 1972 Landesbeauftragter für die Universität Konstanz; 1973 Ehrenbürger von Singen; 1974-86 Präsident der Gesellschaft der Freunde und Förderer der Universität Konstanz. Vgl. Kappes, Bürgermeister, S. 184-189.
} 
ger fungieren dürfen. Bei Otto Feger lag der Fall ähnlich: Der Konstanzer Stadtarchivar trat erst nach Veröffentlichung der Schwäbisch-Alemannischen Demokratie auf Drängen der Landtagsabgeordneten Maria Beyerle in die "vaterländische" BCSV/CDUGruppe Konstanz ein. Hätte sich die konservative Partei wirklich so stark gegen die Autonomieforderungen abgrenzen wollen, wäre eine Parteimitgliedschaft Otto Fegers nicht hinnehmbar gewesen.

Das Programm der BCSV besaß eine gewisse Attraktion, welche die Partei für Bernhard Dietrich und Otto Feger interessant gemacht hat. Auch andere führende Mitglieder des „Schwäbisch-Alemannischen Heimatbundes“ waren schließlich Mitglieder der BCSV, etwa der in Pfullendorf lebende Landtagsabgeordnete Josef Vogt oder der Todtmooser Bürgermeister Leo Götte. Hat es daher von seiten der Autonomisten bis 1947 Einflüsse auf die BCSV gegeben? Von der Hand zu weisen ist das nur schwerlich. Im Umfeld des Parteivorsitzenden Leo Wohleb beschäftigten sich konservative Politiker eingehend mit den Autonomieforderungen der Schwäbisch-Alemannischen Demokratie und des Heimatbundes. Eine BCSV-Denkschrift vom September 1946, die im unmittelbaren Umfeld des Parteivorsitzenden entstanden ist, setzte sich mit dem Verhältnis der BCSV zum Heimatbund auseinander ${ }^{17}$. Dort heißt es: „Die Bestrebungen [...] des ,Schwäbisch-Alemannischen Heimatbundes` entsprechen den Absichten unserer Partei, soweit sie im Bereich des politisch Möglichen liegen und klar formuliert sind." 18 Auf strikte Ablehnung stieß hingegen die Forderung nach Schaffung eines Staates mit eigenen Zollgrenzen, der unmittelbar in eine gesamteuropäische Konföderation eingeflochten sein sollte. Zwei Gründe sprachen gegen zu weitgehende Autonomie: Zum einen wollte die BCSV eine staatenbundliche Lösung für das gesamte Deutschland, zum anderen schienen die Europapläne außerhalb des politisch Realisierbaren zu liegen. Mit Vorbehalt unterstützte der BCSV-Verfasser die Ausarbeitungen einer süddeutschen Konföderation. „Ein Staatswesen Alemannien, welches das gesamte, gegenwärtig französisch besetzte rechtsrheinische Gebiet zusammenfasst [d.i. der Südstaat], womit wir Ziff. $8^{19}$ der Ziele des Heimatbundes unterstützen“, solle gebildet werden, „ohne das neue Staatsgebilde als Vorstufe eines selbständigen Staates anzusehen." 20 Die Passage ist als Reflex auf die französischen Konföderationspläne für Südwestdeutschland vom Frühjahr 1946 zu werten. Die Pläne Koenigs und Saint Hardouins waren nämlich im Rat der Ministeri-

\footnotetext{
17 Die Denkschrift „Schwäbisch-Alemannischer Heimatbund“ vom 2. 9.1946 befindet sich im Nachlaß Leo Wohleb, scheint aber nicht von ihm verfaßt worden zu sein; StA FR T1 NL Leo Wohleb I/1 31.

18 Ebenda.

19 Punkt 8 der Satzung des Heimatbundes: „Als Vorstufe zur Schaffung des selbständigen Schwäbisch-Alemannischen Staates strebt der Heimatbund die Gründung eines Staatswesens an, das die ganze gegenwärtig französisch besetzte Zone des schwäbisch-alemannischen Gebietes umfaßt. In ihm soll eine gemeinsame Regierung und eine gemeinsame Volksvertretung bestimmte Aufgaben für die gesamte Zone durchführen. Im übrigen soll eine weitgehende Selbständigkeit der Landschaften ermöglicht werden." Das „Programmatische Manifest des Schwäbisch-Alemannischen Heimat-Bundes" (NL Bernhard Dietrich und StA FR C 5/1 2749) wurde von Generalsekretär Leopold Paur an die Badische Staatskanzlei übersandt. Von hier aus muß es dem Verfasser der Denkschrift zugänglich gemacht worden sein.

20 Denkschrift ${ }_{n}$ Schwäbisch-Alemannischer Heimatbund“; StA FR T1 NL Leo Wohleb I/1 31.
} 
aldirektoren (Direktorium) ${ }^{21}$, der ab August 1945 als „Badische Landesverwaltung Französisches Besatzungsgebiet " zeichnete, hinlänglich bekannt.

Der Vorsitz des Direktoriums war alternierend; im September 1946 glaubte das Beamtengremium, das vom Leiter der Finanzverwaltung, Alfred Bund ${ }^{22}$ (BCSV), präsidiert wurde, vorpreschen zu müssen, um angesichts der drohenden verwaltungsmäßigen Vereinigung des Südteils der FBZ die eigene Machtposition zu erhalten. In der Denkschrift Zivile Verwaltung der deutschen Gebiete rechts des Rheins [-] französisches Besatzungsgebiet ${ }^{23}$ schlug Bund der französischen Besatzungsmacht folgendes vor: „Für eine eventuelle Zusammenfassung [...] auf dem rechten Rheinufer kämen unter den bestehenden Verhältnissen die Länder Südbaden und Südwürttemberg in Betracht. [...] alle Mitglieder der Landesverwaltung sowie alle politischen Parteien in Baden [stimmen] in vollem Umfang überein [...], daß in einem etwa so zusammenzufassenden neuen Landesgebiet die Militärregierung die Staatsführung nicht Südwürttemberg, sondern Südbaden übertragen müsste." Dazu sei eine Anerkennung der südbadischen Landesverwaltung als Rechtsnachfolgerin der früheren badischen Regierung durch die französische Militärregierung nötig. Im Klartext bedeutete dies, daß nach der von den Amerikanern geschaffenen Vereinigung von Nordwürttemberg und Nordbaden zum Land Württemberg-Baden die Ausdehnung der badischen Staatsverwaltung nach Südwürttemberg erfolgen sollte. Nicht Rottweil oder Tübingen, sondern das „verkehrsgünstig gelegene“ Freiburg sollte nach dem Willen Bunds zum Sitz einer südbadisch-südwürttembergischen Zivilverwaltung werden. Der Südstaat war in den Köpfen der führenden BCSVPolitiker schon Realität.

Innerhalb der BCSV rechnete man demzufolge 1946 mit der Errichtung eines schwäbisch-alemannischen Staates durch Zusammenlegung des französisch besetzten (Süd-) Badens mit Württemberg-Hohenzollern. Nach der Schaffung von Württemberg-Baden durch die Amerikaner im September 1945 hatte auch der in Freiburg für die Justiz zuständige Paul Zürcher ${ }^{24}$ (BCSV) im Gegenzug für den Südstaat plädiert: Es müsse „unter Beachtung der derzeitigen Zonengrenzen mit Nachdruck zur Verwirklichung der staatlichen Einheit der französischen Südzone auf kantonaler Grundlage geschritten wer-

${ }^{21}$ Dem ernannten Beamtengremium gehörten an: Verwaltung und Arbeit: Philipp Martzloff (SPB); Ernährung und Landwirtschaft: Carl Diez (BCSV); Finanzen: Alfred Bund (BCSV); Inneres: Paul Haußer (DP); Justiz: Paul Zürcher (BCSV); Unterricht und Kultus: Karl Ott (parteilos); Wirtschaft: Friedrich Leibbrandt (SPB); vgl. Potthoff/Wenzel, Handbuch, S. 74.

22 Alfred Bund (1882-1975), politisch dem Zentrum verbunden; ab 1907 Karriere im höheren Finanzdienst in Karlsruhe; 1940-44 Aufbau der Steuerverwaltung im Elsaß; 1945 im Rat der Ministerialdirektoren zuerst in Karlsruhe, dann in Freiburg für Finanzen zuständig; Mitglied der BCSV/CDU.

${ }^{23}$ Die Denkschrift ist sowohl als Durchschlag im NL Leo Wohleb (StA FR T1 NL Leo Wohleb I/1 92) als auch im Bestand des HCFA in Colmar (französische Übersetzung) erhalten: „Administration civile des territoires allemands situés au bord droit du Rhin de la Zone Française d'Occupation" vom 20. 9. 1946 (masch. 3 S.); AdO HCFA AP c. 3304 p. 104 d. 1520.

${ }^{24}$ Paul Zürcher (1893-1980), 1920 Abitur in Freiburg i. Br.; 1924 Promotion; 1927 Staatsanwalt in Pforzheim; 1930 Amtsgerichtsrat in St. Blasien, ab 1932 in Freiburg i. Br.; 1944 Rüstungsarbeiter; 1945 kommissarischer Landgerichtspräsident; Chef der deutschen Justiz im französisch besetzten Baden; Mitbegründer der BCSV; 1946 Ministerialdirektor der Justiz; 1947 MdL Baden (BCSV); 1948 Präsident des Oberlandesgerichts Freiburg; politischer Kampf für den Erhalt des Bundeslandes Baden; 1953 Versetzung in den Wartestand; 1958 Pensionierung. Vgl. auch: Knauber, Zürcher. 
den“25. Die französischen Planungen waren Anfang 1946 tatsächlich weit fortgeschritten, sonst hätte die Besatzungsmacht Zürcher nicht aufgefordert, sich für eine Erkundungsreise nach Sigmaringen und Rottweil bereit zu halten, um die Unterbringungsmöglichkeiten für Verwaltungsstellen und Ministerien zu eruieren ${ }^{26}$. Bereits nach wenigen Tagen wurde dem Juristen aber die Annullierung der Anweisung mitgeteilt. Die Deutschen hätten, so die spätere Einschätzung Zürchers, die Zusammenlegung nicht verhindern können, und umgekehrt wäre die Bildung ohne die Zustimmung der französischen Besatzungsmacht nicht möglich gewesen. In Südbaden wäre aufgrund der schlechten Ernährungslage mit wenig Widerstand gegen eine Vereinigung mit Südwürttemberg zu rechnen gewesen. Die Annahme, Paul Zürcher habe 1945/46 ähnliche Pläne wie Otto Feger erörtert ${ }^{27}$, ist folglich nicht aus der Luft gegriffen. Wegen seiner späteren Aktivitäten wurde Zürcher jedoch nicht grundlos als die Inkarnation des „Altbadeners“ erachtet, vertrat er doch in späteren Jahren mit unglaublicher Vehemenz die Wiederherstellung der Eigenstaatlichkeit Badens.

Im April 1947 zitierte der Freiburger Oberbürgermeister und BCSV-Fraktionsvorsitzende Dr. Wolfgang Hoffmann ${ }^{28}$ in der Beratenden Landesversammlung ganze Passagen aus Fegers Schwäbisch-Alemannischer Demokratie. Die föderalistischen und antipreuBischen Argumente Fegers trug Hoffmann in extenso vor, zugespitzt in der Forderung, „Herren im eigenen Hause sein oder werden " 29 zu wollen. Die autonomistischen Gedanken rezipierte Hoffmann bis hin zur Vorstellung eines deutschen Staatenbundes, von dem Baden nicht „separiert" sein werde. Wenngleich Hoffmann dem badischen Staat den Vorzug gab, schloß er eine "schwäbisch-alemannische Autonomie“ nicht aus, nach

${ }^{25}$ Paul Zürcher: Soll Baden eines gewaltsamen Todes sterben?, in: Südwestdeutsche Volkszeitung vom 9. 11. 1946. Wiederabgedruckt u. a. in der Schwarzwälder Post vom 15. 11. 1946. Zürcher fuhr mit seinen Bemerkungen folgendermaßen fort: „Nur diese Lösung könnte Baden jene Einbuße an landwirtschaftlichen und industriellen Gebieten ersetzen, die es durch Entreißung seiner nördlichen Landesteile erleiden würde. Nur in dieser Form wäre einheitlich der badisch-württembergische Süden lebensfähig."

${ }^{26}$ Ein Jahrzehnt später sah sich Paul Zürcher als Replik auf eine provozierende These des badenwürttembergischen Ministerpräsidenten Gebhard Müller genötigt, die Zusammenhänge und Ereignisse um die mögliche Neugliederung in den Jahren 1945/46 aus seiner Sicht zu verdeutlichen; [Zürçher], Süd-Staat.

${ }^{27}$ Zur Verifizierung der These müßte der Nachlaß Zürcher ausgewertet werden, über dessen Existenz nichts bekannt ist. Zur These selbst: Krautkrämer, Ringen, S. 235. Ähnliche Überlegungen bei Paul Rothmund: „Südbadens ,Graue Eminenz', Dr. Zürcher, erwog im Rückgriff auf Feger eine kantonale Gliederung mit einer Bundesregierung in Konstanz oder auch in Bad Dürrheim“; Rothmund, Neubeginn, S. 11.

28 Wolfgang Hoffmann (1893-1956), Besuch des Lyzeums in Straßburg und des Bertholdgymnasiums in Freiburg i. Br., Rechtsstudium an den Universitäten Freiburg und Straßburg; Promotion; Mitglied der katholischen Studentenverbindung „Wildenstein“ (CV) in Freiburg; 1914-18 Kriegsteilnehmer; im höheren Dienst bei der badischen Innenverwaltung in Freiburg tätig; 192533 MdL Baden (Zentrum); 1933 von der Position eines Regierungsrates abgesetzt; 1939 Syndikus bei einer Freiburger Firma; 1944 Verhaftung durch die Gestapo; 1945 Mitglied der Zentrumsgruppe; 1946 Stadtrat und Oberbürgermeister in Freiburg (BCSV); 1947-52 MdL Baden (CDU), bis 1949 Fraktionsvorsitzender der BCSV/CDU. Vgl. Rößler, Landtag, S. 121.

${ }^{29}$ Zur Rede Hoffmanns vor der Beratenden Versammlung in Freiburg vom 10. 4. 1947 vgl. Verhandlungen der Beratenden Landesversammlung des Landes Baden, 1946-1947, S. 7-11, hier S. 10; StA FR $10 \mathrm{Zf}$. 
dem Motto: „Nicht drängen, es wird sich alles, alles finden“30. Im übrigen diente Hoffmann der Versuch, die Schuld am „Dritten Reich“ auf den preußischen Zentralismus und Militarismus zu schieben, dazu, nicht weiter über die Ursachen nachdenken zu müssen. Von der „Unerschütterlichkeit des Alemannenstandes gegenüber dem Nationalsozialismus" gab er sich allerorten überzeugt ${ }^{31}$.

Der spätere Generalsekretär der Vereinigung Südwest ${ }^{32}$, der Freiburger Stadtrat Albert Maria Lehr ${ }^{33}$ (BCSV), vertrat Anfang 1947 einen ausgeprägt föderalistischen Standpunkt. Die neugebildeten Länder müßten „den deutschen Stämmen oder einer langen, ganz besonderen Entwicklung entsprechen" 34 . Vorbildfunktion für eine staatliche Reorganisation Deutschlands hatte die "Schweizer Konföderation" 35 , auch Lehr blickte wie viele südwestdeutsche Politiker aller couleur verlegen über die Grenze im Süden. Nach dem Prinzip der Subsidiarität sollten die Länder sich selbst regieren und verwalten, sich gleichzeitig aber mit einem Bund verbinden, „in dem sich eine Reihe gleichberechtigter Partner zur gegenseitigen Hilfe und Lösung gemeinsamer Aufgaben zusammenfin$\operatorname{det}^{\text {"36. }}$.

Auch Leo Wohleb ${ }^{37}$, seit 3. Dezember 1946 Präsident des Staatssekretariats „Provisorische Landesregierung“ und ab Mai 1947 Badischer Staatspräsident, wußte nur zu genau um die unausgegorenen Planungen der französischen Besatzungsmacht. Der vormalige Hochschulreferent scheint 1945 zeitweise - so berichtete sein Parteifreund Heinz Bollinger ${ }^{38}$, der auch intensiven Kontakt zu Josef Ruby und der „Vereinigung Abendland“ pflegte - einen Zusammenschluß von Baden mit dem Elsaß erwogen zu haben ${ }^{39}$.

${ }^{30}$ Ebenda, S. 10.

${ }^{31}$ Fäßler, Hauptstadt, S. 384.

32 Vgl. dazu Bury, Volksentscheid.

33 Albert Maria Lehr ("1913), in einer Freiburger Zentrums-Familie aufgewachsen; Ingenieurstudium; 1945 Bürgermeister von Lenzkirch (Schwarzwald); zusammen mit Peter Pfeiffer Aufbau der BCSV im Kreis Neustadt; Stadtrat in Freiburg (BCSV); Studium der Theologie. Zu Lehr vgl. auch den Artikel: „Bürgermeister wider Willen wurde zu einem der CDU-Gründerväter“, in: Südkurier vom 22. 5. 1995.

${ }^{34}$ A[lbert] M[aria] L[ehr]: Föderalismus?, in: Südwestdeutsche Volkszeitung vom 15. 3. 1947.

${ }^{35}$ Ebenda.

${ }^{36}$ Ebenda.

${ }^{37}$ Leo Wohleb (1888-1955), Studium der Altphilologie und der Patristik; Lehrtätigkeit an verschiedenen badischen Gymnasien; Hilfsreferent im badischen Unterrichtsministerium; 1934-45 Direktor des Gymnasiums Hohenbaden in Baden-Baden; 1945 Hochschulreferent im Unterrichtsministerium in Karlsruhe, dann Freiburg; Mitbegründer und 1945-47 Landesvorsitzender der BCSV; 1947-52 Badischer Staatspräsident und MdL; 1952-55 deutscher Botschafter in Lissabon. Zur Biographie Wohlebs vgl. die Arbeiten von Paul-Ludwig Weinacht: Ders., Wohleb, 1975; Ders., Regierungsjahre; Ders., Wohleb, 1990; Ders., Standpunkt; Ders., Wohleb, 1991; Ders., Einheit.

${ }^{38}$ Heinz Bollinger (1916-1990), 1938-40 Studium in Freiburg i. Br. und München; 1942 Promotion; Assistent an der Philosophischen Fakultät; 1943 wegen Widerstandsarbeit (,Weiße Rose") zu 7 Jahren Zuchthaus verurteilt; 1946 Stadtrat in Freiburg (BCSV); Geschäftsführer der Volkshochschule.

39 Dem Historiker Heiko Haumann gab Bollinger 1987 zu Protokoll, er habe sich mit Wohleb heftig in Gegenwart von französischen Offizieren über die Pläne einer von Wohleb befürworteten Vereinigung von Baden und dem Elsaß gestritten; Interviewprotokoll vom 25. 11. 1987; StadtA FR M2/107. Tatsächlich hatte ein französischer Offizier, Winninger, im Jahr 1945 eine Vielzahl von Gesprächen über eine mögliche Vereinigung von Baden mit dem Elsaß samt Eingliederung in den französischen Staat im südbadischen Raum geführt. Seine Ergebnisse teilte er am 7.2. 1946 
Wenngleich sich Leo Wohleb in der Öffentlichkeit als „Hüter der badischen Tradition“ zu erkennen gab ${ }^{40}$, mußte er als Vorsitzender der BCSV 1946 jederzeit mit der Möglichkeit einer verwaltungsmäßigen Umgestaltung des Südteils der Französischen Besatzungszone rechnen, die zwangsläufig auch parteipolitische Konsequenzen nach sich gezogen hätte. Schon deshalb konnte er 1946 nicht gegen die Fegersche Stammesstaatsidee Front machen ${ }^{41}$. Denn eine Badische Christlich Soziale Volkspartei hätte schwerlich in Südwürttemberg-Hohenzollern auf Stimmenfang gehen können. Deshalb mußte Wohleb 1946/47 versuchen, die Partei für eine mögliche Erweiterung offenzuhalten. In diesem Zusammenhang ist auch die BCSV-interne Denkschrift über den „SchwäbischAlemannischen Heimatbund" einzuordnen. Tatsächlich stand Wohleb unmittelbar nach 1945 einer Vereinigung von Südbaden mit Südwürttemberg-Hohenzollern zu einem Südstaat wohlwollend gegenüber. Auf dem Gründungsparteitag der christlichen Partei im Februar 1946 in Freiburg gab er dem Landwirt und späteren BCSV-Kreisrat von Überlingen, Albert Hammer, zu verstehen, daß er der Idee des Südstaates „sympathisch

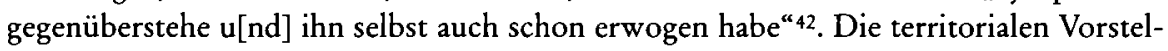
lungen Wohlebs stimmten ein Jahr nach Kriegsende weitgehend mit den Zielen des Heimatbundes überein. Auch die Frage des Staatsbürgerrechts tangierte spätestens seit Beginn der Südweststaatsverhandlungen den Badischen Staatspräsidenten. Sprach der Heimatbund 1946 von dem vage definierten Begriff des „Bodenständigen“, der die alleinige politische Mitsprache innehaben sollte, so definierte Wohleb 1948 von der anderen Seite aus den "Landfremden“, der nach dem 1. September 1939 oder seit April 1945 in Südwestdeutschland ansässig sei. Die „Landfremden“ hatten nach Wohlebs Auffassung kein „inneres Verhältnis“ zu Ländergrenzfragen ${ }^{43}$. Der Badische Staatspräsident vermutete, daß die einheimische Bevölkerung es nicht verstehen könnte, wenn „Landfremde über das Schicksal der Länder entscheiden“ würden. Auch in diesem Punkt deckten sich die Vorstellungen Wohlebs mit dem Programm des Heimatbundes.

dem SGAAA in Paris mit; AdO SGAAA c. 2664 9. séparatisme. Winninger kam zu dem Schluß, daß 80\% der südbadischen Bevölkerung einen Anschluß an Frankreich begrüßten, nicht zuletzt, weil „die Sitten und Gebräuche" in Baden und im Elsaß identisch seien. Besonders die Wirtschaft sei von dieser Lösung angetan, und die Bevölkerung könne man, so Winninger, durch die sofortige Freilassung der südbadischen Kriegsgefangenen auf die Pläne einstimmen.

${ }^{40}$ Etwa in seinem Artikel „Badnerland, Heimatland!" in der Badischen Zeitung vom 31. 5. 1946, den er mit den Worten enden ließ: „Wir sind Hüter der badischen Tradition aus guten Vernunftund Gefühlsgründen. Die Begriffe ,Nordbaden' und ,Südbaden` sind uns nicht geläufig. Unser Heimatland ist das Badnerland ungeteilt."

${ }^{41}$ Die These wurde von Paul-Ludwig Weinacht vertreten, der allerdings die Ambivalenz zwischen dem Auftreten Wohlebs in der Öffentlichkeit und dessen politischem Kalkül übersieht; Ders., Kultur, S. 234.

${ }^{42}$ Hammer an Wohleb vom 17. 12. 1950; StA FR T1 NL Leo Wohleb I/1 66.

Albert Hammer, Bürgermeister von Wittenhofen und Gründungsmitglied der BCSV im Kreis Überlingen (Weinacht, Ursprung, S. 94), redete 1946 auf dem BCSV-Parteitag einer Neugliederung Südwestdeutschlands das Wort. Er schlug die Bildung eines Landes „Südbaden, Südwürttemberg mit Hohenzollern allerdings nicht mit der Hauptstadt in Tübingen oder Freiburg sondern in Sigmaringen, evtl. Donaueschingen " vor; ebenda. Als Hauptargumente führte er die Verwaltungsvereinfachung, die Verbesserung der Ernährungslage und die konfessionelle und stammesmäßige Homogenität an (, Wir bekämen ein überwiegend kath. Land mit stammesmäßig gleicher Bevölkerung (Schwaben)"; ebenda.

${ }^{43}$ Konstanzer, Entstehung, S. 136. 
Spätestens seit Ende 1946 - wahrscheinlich aber schon früher - verfügte der Badische Staatspräsident auch über direkte Kontakte zur Autonomieszene. „Unter Bezugnahme auf die seinerzeitige Besprechung in Überlingen über die Ziele des, Schwäbisch-Alemannischen Heimatbundes“", ließ Generalsekretär Paur ein Schreiben an Leo Wohleb im Dezember 1946 beginnen $^{44}$, dem die Satzungen und das Manifest beigefügt waren. Allerdings beschränkten sich die Wohlebschen Kontakte auf gelegentliche „konspirative“ Treffen und mündliche Aussprachen, von denen weiter nichts Schriftliches erhalten ist. Tunlichst vermied es Wohleb, mit dem Heimatbund zu korrespondieren, vielmehr traf er selbst oder seine Vertrauensmänner persönlich oder telephonisch mit Paur und Dietrich zusammen. „Unter Bezugnahme auf unsere letzte Besprechung in Freiburg“, schrieb der Generalsekretär des Heimatbundes im Januar 1948 an Wohleb, „erlaube ich mir, an Sie die höfliche Bitte zu richten, den von Ihnen in Aussicht genommenen Vertrauensmann nächste Woche nach Singen, Hegaustrasse $N^{\circ} 2$ zu senden. “45 Der Vorsitzende der BCSV/CDU hegte nämlich die Befürchtung, daß der Heimatbund das christliche Wählerpotential spalten könnte, was unter allen Umständen zu vermeiden war. Aber der Heimatbund war nicht als Partei, sondern als Vereinigung konzipiert worden. Demzufolge legte Paur im März 1948 Wert auf die Aussage, „daß wir [der Heimatbund] nach wie vor an dem festhalten, was Herr Dr. Dietrich und ich mit Ihnen besprochen haben, denn es liegt uns vollkommen fern, eine Sprengung in die heimatlichen christlichen Kreise zu tragen " ${ }^{46}$. Der einseitige Schriftwechsel des Heimatbundes mit Leo Wohleb belegt die Gefahr, die dessen Existenz in den Augen der nunmehr CDU Baden genannten BCSV darstellte. Aber Wohleb war sich 1948 sicher, daß der Heimatbund seinen Zenit bereits überschritten hatte. Wiederum durch einen mit Interna über den Heimatbund gespickten Brief Paurs ${ }^{47}$ wurde er in seiner Haltung bestärkt, zwar in persönlichen Gesprächen mit dem Heimatbund in Kontakt zu bleiben, ihm aber aufgrund der personellen Konstellationen für die nahe Zukunft keine größere Gefahr mehr beizumessen. Dennoch mußte er vor seinem geistigen Auge mit der Bildung einer Art Bayerischen Volkspartei im südbadischen Raum rechnen, was zumindest zu einer Schwächung der Position der CDU geführt hätte. Daher sah sich Wohleb veranlaßt, auch weiterhin Sondierungsgespräche mit Dietrich zu führen. „Bei unseren verschiedenen Besuchen habe ich Ihnen offen und freimütig meine Haltung gegenüber der CDU dargelegt und ich glaube, $\mathrm{daß}$ Sie an meinem loyalen Verhalten nicht zweifeln“, gab Bernhard Dietrich dem Badischen Staatspräsidenten im März 1948 zu verstehen ${ }^{48}$.

Dem Generalsekretär des "Schwäbisch-Alemannischen Heimatbundes“, Dr. Leopold Paur ${ }^{49}$, sollte noch eine denkwürdige Karriere unter den Fittichen Leo Wohlebs bevor-

44 Paur an Wohleb vom 5. 12. 1946; StA FR C 5/1 2749.

45 Paur an Wohleb vom 22. 1. 1948; StA FR T1 NL Leo Wohleb I/1 91.

46 Paur an Wohleb vom 19.3. 1948; ebenda.

47 Paur an Wohleb vom 21.8. 1948; ebenda.

${ }^{48}$ Der Präsident des „Schwäbisch-Alemannischen Heimatbundes" an Wohleb vom 8. 3. 1948; StA FR T1 Leo Wohleb I/1 53.

49 Leopold Paur (1889-1979), 1908 Abitur an einem humanistischen Gymnasium in München; 1908-12 Juristisches Studium in München; 1912 Referendarsexamen; 1914-18 Kriegsteilnehmer (Leutnant d. R.); 1918 Promotion in Heidelberg; 1919 Assessorexamen für den höheren Justizund Verwaltungsdienst in München; 1919-20 Rechtsanwalt in München; 1920-24 Stellvertretender Reichsbevollmächtigter der Außenhandelsstelle "Chemie“ und Leiter der Nebenstelle „Harze“ in Hamburg; 1924-45 als Syndikus und Leiter von verschiedenen Verbänden in Berlin 
stehen. Seine Kontakte zum Badischen Staatspräsidenten pflegte er über Jahre, dank seines Auftretens und seiner Überzeugungskraft hatte er einen tiefen Eindruck bei Wohleb hinterlassen. Als promovierter, aber arbeitsloser Jurist lebte Paur bis zur Währungsreform von einem nicht unbeträchtlichen Vermögen, das er allerdings durch die Währungsumstellung größtenteils verlor. Noch 1948 bewarb er sich um die Stelle des Überlinger Landrates, ein Ansinnen, das beim badischen Innenminister Alfred Schühly (CDU) auf Ablehnung stieß. Bereits ab Ende 1949 verfügte Paur über direkte Kontakte in die Badische Staatskanzlei, bei der Probeabstimmung für den Südweststaat hatte er 1950 ein reiches Betätigungsfeld gefunden. Seine Wendung war vollkommen: Bis 1948 forderte er einen autonomen schwäbisch-alemannischen Staat, im Gefolge von Leo Wohleb erwies er sich als intransigenter „Altbadener“. Sein Engagement bei der Probeabstimmung zog die ungeteilte Aufmerksamkeit Wohlebs auf sich, das 1951 mit dem Posten des Dezernenten der Pressestelle in der Badischen Staatskanzlei belohnt wurde. Vollkommen von der Öffentlichkeit abgeschirmt und selbst im Umfeld Wohlebs unbemerkt $t^{50}$, hatte Paur die Aufgabe, für den Badischen Staatspräsidenten Vorträge und Zeitungsartikel zu verfassen und Korrespondenzen im Zusammenhang mit der Länderneugliederung zu erledigen; der promovierte Jurist erhielt von Wohleb die mündliche $\mathrm{Zu}$ sage, nach einer für Baden günstigen Volksabstimmung zum beamteten Leiter der Pressestelle der Staatskanzlei ernannt zu werden ${ }^{51}$. Überhaupt arbeitete Paur, der mittlerweile von Engen nach Freiburg umgezogen war, als rechte Hand Wohlebs in der BadenFrage. Sämtliche, die Neugliederung der südwestdeutschen Länder betreffenden Korrespondenzen an Wohleb gelangten zwecks Beantwortung in Paurs Hände ${ }^{52}$. Nach der schmerzlichen Niederlage bei der Volksabstimmung vom Dezember 1951 trug Wohleb Sorge dafür, daß sich Paur als Stiftungsrat der Universität Freiburg eine berufliche Perspektive eröffnete.

Das Einschwenken der BCSV auf die territorialen und landsmannschaftlichen Vorstellungen des "Schwäbisch-Alemannischen Heimatbundes“ angesichts der vermeintlich sicheren Bildung des Südstaates im Jahr 1946 durch die französische Besatzungsmacht ist evident. Innerhalb der Führungsschicht der Partei in Freiburg stießen die Pla-

tätig; 1938 Schwierigkeiten wegen Nichtmitgliedschaft in der NSDAP bei Bekleidung einer hohen Position in der Wirtschaft; 1941-44 Hauptmann d. R. im Heereswaffenamt in Berlin; 1944 Übersiedlung nach Engen/Hegau mit den von Berlin nach Engen verlagerten und in Fachabteilungen umgebildeten Wirtschaftsverbänden; 1945 durch die Auflösung sämtlicher Fachabteilungen arbeitslos; 1946-49 Generalsekretär des "Schwäbisch-Alemannischen Heimatbundes“; Propagandist für die europäische Einigung (vgl. seine Rolle in der „Europäischen Zentralbewegung für die Vereinigten Staaten von Europa" in Kapitel V/2); 1950 Einsatz für den Erhalt des badischen Staates; 1951-52 Dezernent in der Pressestelle der Badischen Staatskanzlei; 1952 Stiftungsverwalter der Universität Freiburg i. Br.; mehrmalige Verlängerung des Arbeitsverhältnisses bis 1961. Vgl. die Personalakte im Universitätsarchiv in Freiburg; UA FR B 24/2744.

${ }^{50}$ Ein Mitarbeiter Wohlebs in der Badischen Staatskanzlei zu Beginn der fünfziger Jahre, Paul Feuchte, konnte sich nicht an die Anwesenheit Paurs erinnern, gab aber zu bedenken, daß die Organisation einer Staatskanzlei nicht mit dem straffen Gefüge späterer Jahre zu vergleichen gewesen sei; Telefonat des Verfassers mit Paul Feuchte vom 24. 3. 1995.

51 "Lebenslauf von Dr. jur. Leopold Paur“" [1953]; UA FR B 24/2744.

52 In dem mehrere tausend Briefe umfassenden Nachlaß Leo Wohleb tragen alle ab 1950 die Neugliederung betreffenden Schreiben an Wohleb dessen handschriftlichen Vermerk "Dr. Paur“. Die Briefe wurden also Paur im Presseamt zur Beantwortung vorgelegt. Damit war Paur im engsten Umfeld des Badischen Staatspräsidenten tätig. 
nungen unter Verzicht auf die Forderung nach Autonomie auf keinen nennenswerten Widerstand, Politiker wie Alfred Bund, Leo Wohleb oder Paul Zürcher suchten nach Wegen und Möglichkeiten der Machterhaltung im neuen Staat, dessen Zentrum nicht unbedingt Freiburg sein würde. Das Einschwenken der BCSV auf die „altbadische“ Linie, das zwar schon 1946 in der Öffentlichkeit zu beobachten war, fand allerdings erst Ende 1947 mit dem eindeutigen Wechsel der französischen Besatzungspolitik in Richtung Wiederherstellung der alten Länder statt. Sinnfälligster Ausdruck hierfür ist die Umbennung von BCSV in CDU-Baden, die auf die Zusammenarbeit mit den nordbadischen Parteifreunden abzielte. Auch die internen Querelen bei der Bildung des Südweststaates sind als letzter Abglanz der Neugliederungsdebatte zu werten. Viele BCSV/ CDU-Parteimitglieder konnten dem offiziellen Kurs ihrer Partei nicht folgen, da sie unmittelbar nach 1945 zu den Anhängern einer schwäbisch-alemannischen Demokratie zählten; sie erachteten das Bundesland Baden-Württemberg als das einzig politisch machbare Gebilde auf weitgehend stämmischer Basis, eine Position im übrigen, die selbst Otto Feger geteilt hat.

\section{Die CDU in Württemberg-Hobenzollern}

Wie die BCSV in Baden, verfügte auch die CDU in Württemberg-Hohenzollern über Männer in ihren Reihen, die - wenn auch oft nur hinter vorgehaltener Hand - von der Notwendigkeit einer Neugliederung Südwestdeutschlands bei gleichzeitig weitgehender Autonomie im Rahmen eines deutschen oder europäischen Staatenbundes überzeugt waren. Auch von der Parteibasis kamen gelegentlich solche Vorschläge ${ }^{53}$. Das Ergebnis einer im März 1947 im Kreis Ehingen durchgeführten Umfrage ${ }^{54}$ ergab ein für das konservativ-katholische Württemberg-Hohenzollern repräsentatives Bild: Berlin als zukünftige Hauptstadt eines deutschen Staates wurde entschieden abgelehnt, eine Reminiszenz an die vorderösterreichische Zeit wehte durch das Stimmungsbild. Immerhin ein Drittel der Befragten - vor allem „Traditionalisten, Monarchisten, Großgrundbesitzer und ein kleiner Teil des katholischen Klerus ${ }^{* 55}$ - neigten einer staatenbundlichen Lösung unter Ausschluß des Nordens zu, einer alpinen Union also; Autonomie für den geeinten schwäbisch-alemannischen Raum galt ihnen als unabdingbar. Der Tübinger Oberdelegierte Widmer glaubte zudem Anfang 1947, daß sich die politischen Konzepte vieler konservativ-christlicher Politiker in Württemberg-Hohenzollern in den beiden

${ }^{53}$ In einer politischen Aufzeichnung von Fr[iedrich] Nerz aus Beuren (Landkreis Hechingen) im Archiv des Landesverbandes der CDU Württemberg-Hohenzollern ist folgender Vorschlag nachzulesen: „Teilung Deutschlands - politisch - in zwei Hälften, in einen Nord- und einen Südbund. Trennung durch die Mainlinie. Weitere Aufspaltung der zwei Bünde, Germaniens' in Kantone (nach Schweizer Vorbild) [...] Neuer politischer Zusammenschluß zu einem Mittel-Europa. Bund der zwei Bünde mit der Schweiz, mit der Tschechoslowakei, mit Österreich, mit Ungarn, mit Dänemark und den Niederlanden. Garantie der Neutralität dieses Gebietes durch die Vereinten Nationen“; zitiert nach Wieck, Demokraten, S. 170 Anmerkung 291.

54 "Sondage de l'opinion" (masch. 9 S.); Noutary an Widmer vom 10. 3. 1947; AdO W-H 1f) Ser. Div. c. 2561. Der Ehinger Kreisdelegierte Noutary verschickte an 128 Personen einen Fragebogen zur künftigen staatlichen Organisation Deutschlands, den diese anonym ausfüllten und zurückgaben. Eine Präponderanz des katholisch-konservativen Milieus, die den Verhältnissen im Kreis Ehingen entsprach, ist zu konstatieren.

55 Ebenda, S. 7. 
vorausgegangenen Jahren bereits von einer staatenbündischen zu einer bundesstaatlichen Lösung gewandelt hätten 56 , ein Indiz für die Abmilderung von Autonomieforderungen binnen kurzer Zeit. Hatten die Protagonisten der CDU Württemberg-Hohenzollern unmittelbar nach 1945 konkrete Vorstellungen oder Konzepte von der zukünftigen Organisation und den staatsrechtlichen Verhältnissen des Südwestens?

Der Gründer der CDU in Oberschwaben, Dr. Franz Weiß ${ }^{57}$, wurde im Frühsommer 1945 von General Schwartz in Stuttgart zum Landesdirektor für Landwirtschaft und Ernährung eingesetzt. Durch die Parteigründung in der amerikanischen Zone veranlaßt, besuchte Weiß in den letzten Monaten des Jahres 1945 mit einem geliehenen, alten Opel P4 die Kreise des französisch besetzten Württembergs und Hohenzollerns, um politisch interessierte Persönlichkeiten von der Notwendigkeit der Gründung einer christlichen Partei zu überzeugen ${ }^{58}$. Eine Versammlung wurde am 6. Januar 1946 im Gemeindesaal in Aulendorf abgehalten, bei der Weiß das einführende Referat hielt. Die Gründung der Christlich Demokratischen Union in Württemberg-Hohenzollern wurde beschlossen. Auf der ersten Landesversammlung am 23. März 1946 in Sigmaringen wählten die Delegierten Franz Weiß zum Vorsitzenden des vorläufigen Landesausschusses. Die Haltung des ersten Landesvorsitzenden war ambivalent: Katholisch, frankophil und antipreuBisch gesinnt, konnte er sich nicht für die Umsetzung eines autonomistischen Kurses in der CDU Württemberg-Hohenzollern entschließen; Weiß scheint eher ein Anhänger eines südwestdeutschen Länderzusammenschlusses gewesen zu sein, der in einem föderativ aufgebauten Bundesstaat verankert sein sollte. Französische Beobachter schätzten seine innerparteiliche Autorität überdies als schwach ein ${ }^{59}$, klare Stellungnahmen zu der Problematik vermied Weiß ${ }^{60}$.

Als "Theoretiker und Propagandisten des schwäbischen Partikularismus“ bezeichnete Ende 1947 der Sigmaringer Kreisdelegierte Chevallier in einem Brief an die Tübinger Oberdelegation ${ }^{61}$ den Stellvertretenden Landeshauptmann von Hohenzollern und Sigmaringer Bürgermeister Egon Müller ${ }^{62}$. In der Tat war Müller ein überzeugter Anhänger einer Großschwaben-Lösung, die auf einer südwestdeutschen Konföderation

56 "Il [Widmer] note que beaucoup de leaders catholiques, à l'origine, partisans d'une Fédération d'Etats, en sont maintenant venus à la conception d'un Etat Fédéral ", Sitzung des CGAAA in Paris vom 13. 1. 1947; MAE Y-Int. 1944-1949654.

57 Franz Weiß (1887-1974), Studium der Landwirtschaft in Halle a. d. S., Hohenheim und Gießen; 1910 Eintritt in die katholische Studentenverbindung "Carolingia " im CV (Hohenheim); 1912 Landwirtschaftslehrer in Stromberg (Westfalen); 1913-20 Mitarbeit in der Landessaatzuchtanstalt in Hohenheim, 1920-33 Leiter der Abteilung Pflanzenbau der Württembergischen Landwirtschaftskammer in Stuttgart; seit 1934 Geschäftsführer des Württembergischen Getreidewirtschaftsverbandes, später des Kartoffelwirtschaftsverbandes; 1945 Landesdirektor für Ernährung und Landwirtschaft in Württemberg-Baden; 1946 Landesdirektor für Landwirtschaft und Ernährung in Württemberg-Hohenzollern; 1947-52 Minister für Landwirtschaft und Ernährung; 1949-53 MdB (CDU). Vgl. Dornheim, Adel, S. 406 Anmerkung 147.

${ }_{58}$ Weiß, Gründungszeit, S. 13.

${ }^{59}$ Hauptmann de Lacger: „Objet: La Bavière et le problème allemand“ (masch. 28 S.) vom 2. 2. 1946; MAE Z-Europe 1944-1960 61.

${ }^{60}$ Der Nachlaß im StA SIG (N 1/1) enthält keinen Hinweis auf die Position von Franz Weiß in der Frage der Neugliederung.

${ }^{61}$ Chevallier an Widmer vom 27. 12. 1947; AdO SGAAA Dir. Pol. c. 43 F10.

62 Egon Müller (1885-1949), Bürgermeister von Sigmaringen und Stellvertretender Landeshauptmann beim Hohenzollerischen Landesverband. 
beruhen sollte. Ausgeprägt autonome Mitglieder des Bundes sollten die Nord- und Südhälften der Länder Baden und Württemberg sowie der ehemalige preußische Regierungsbezirk Hohenzollern sein. Mit Denkschriften von 1946 und $1949^{63}$ versuchte der Sigmaringer Bürgermeister gleichzeitig die staatliche Eigenständigkeit der Hohenzollerischen Lande zu belegen und jeden Rechtsanspruch der Tübinger Regierung zurückzuweisen. Nach Müllers Tod 1949 sind in dessen Handakten Unterlagen gefunden worden, die frühere Besprechungen über einen Südstaat belegt haben ${ }^{64}$.

Der Besitzer eines 85 Hektar umfassenden Hofgutes in Dürren bei Ravensburg, Oskar Farny ${ }^{65}$, spielte wegen seiner zwielichtigen Vergangenheit als Reichstagsabgeordneter bis Kriegsende und als Chef des Stabes des Kommandeurs der Kriegsgefangenen im Wehrkreis V (Stuttgart) eine oberflächlich unbedeutende Rolle. Durch die ablehnende Haltung der Wangener CDU-Repräsentanten Josef Lutz und Richard Abt wurde Farny zunächst nicht in der CDU aufgenommen, er konnte sich aber als Besitzer einer Jagdhütte im bayerischen Allgäu als CSU-Mitglied etablieren ${ }^{66}$. Abgesehen von einem kurzen Intermezzo als Leiter des Landesernährungsamtes in Württemberg-Hohenzollern, bekleidete er mangels fehlender CDU-Mitgliedschaft bis Ende der vierziger Jahre kein hohes Regierungsamt. Doch auf der informellen Ebene spielte er eine entscheidende Rolle: Sein großer Gutshof wurde zu einem beliebten Ausflugsziel bei der Politprominenz von Württemberg-Hohenzollern, fürstlich bewirtete er zuweilen Carlo Schmid, Paul Binder und Gebhard Müller. Überparteilich organisierte Fahrten zu Farny waren angesichts der Lebensmittelknappheit an der Tagesordnung.

Schon zu einem frühen Zeitpunkt gab er sich als ein Verfechter des Zusammenschlusses von Baden und Württemberg zu erkennen und nutzte die informellen Treffen mit den hochrangigen Politikern, um sie für einen zukünftigen Zusammenschluß der auf dynastischer Grundlage gebildeten Länder einzustimmen. Auch gegenüber der französischen Besatzungsmacht vertrat Farny die Linie eines geeinten Südwestens in einem föderalistisch aufgebauten Deutschland. Bei einer Besprechung mit dem Oberdelegierten Widmer am 12. Dezember $1947^{67}$ brachte er zum Ausdruck, „daß wir in Süddeutschland

${ }^{63}$ Denkschrift des Landeshauptmannes von Hohenzollern, überreicht am 8. 3. 1949; StA SIG Wü 2/606/3/1/2.

${ }^{64}$ Bericht der „Arbeitsgemeinschaft der CDU der hohenzollerischen Kreise“ an Staatspräsident Gebhard Müller vom 12. 7. 1950; zitiert nach Nüske, Hohenzollernfrage, S. 181.

${ }^{65}$ Oskar Farny (1891-1983), Gutsbesitzersohn aus Dürren bei Ravensburg; Gymnasium in Ravensburg; kurzzeitiges Studium in Tübingen, Eintritt in die katholische Verbindung „Guestfalia“ im CV; 1910 Offiziersanwärter beim Infanterie-Regiment Nr. 124 in Weingarten; 1914-19 Kriegsteilnehmer (Hauptmann d. R.); 1920-21 MdL Württemberg (Zentrum); 1930-45 MdR; nach 1933 Führungspositionen in der Verwaltung der Lebensmittelindustrie; 1939-45 Chef des Stabes des Kommandeurs der Kriegsgefangenen im Wehrkreis V; 1946 Leiter des Landesernährungsamtes; Südweststaatsanhänger; 1950 Mitglied der „Arbeitsgemeinschaft für die Vereinigung Baden-Württemberg “; 1952 MdL Baden-Württemberg (CDU); 1953-60 Leiter des Ministeriums für Bundesangelegenheiten des Landes Baden-Württemberg; 1954-67 Präsident des vormaligen Württembergischen Landesverbandes der Raiffeisengenossenschaften. Vgl. Dornheim, Adel, S. 375-379 und o. A., Farny.

${ }^{66}$ Dornheim, Adel, S. 278.

${ }^{67}$ Neben Widmer nahmen an dem Gespräch teil: Lutz (Leutkirch), Hartmann (Oflings), Farny (Dürren), Paprzycki (Wangen), Maier (Wangen) und Kiechle (Wangen). Der Wangener Landrat Kiechle fertigte aus den Protokollen der Teilnehmer einen Bericht für Widmer an; KA RV NL Münch 44.2. 
nach den Erfahrungen der letzten 30 Jahre den zentralistischen Einheitsstaat unter preuBisch-berlinerischer Hegemonie ablehnen und ein föderatives Staatensystem mit gesichertem Eigenleben der süddeutschen Kulturkreise bevorzugen"68. Die wirtschaftliche Entwicklung seit 1870 erachtete Farny als irreversibel, und deshalb lehnte er jede "Zwergstaatlösung “69 in Südwestdeutschland ab. Eine verwaltungsmäßige Zusammenfassung des Südteils der französischen Zone schloß er aus, vielmehr könne nur „eine überstaatliche europäische Gemeinschaftsidee " die Antwort auf die Katastrophe des Zweiten Weltkriegs sein 70 .

Der enge politische Anschluß des deutschen Südwestens an Österreich, den Fürst Erich von Waldburg-Zeil vertreten hat, fand manchen Zuspruch in den Kreisen des oberschwäbischen Adels, weniger aber innerhalb der CDU von Württemberg-Hohenzollern. Grundlage einer süddeutschen, katholischen Föderation war für den Fürsten allerdings ein stammesmäßig gegliedertes Süddeutschland. Für den Südwesten sprach sich Fürst Erich zugunsten einer Einbeziehung von Bayerisch-Schwaben in einen großschwäbischen Staat aus. Dazu hatte er in Ravensburg ein Komitee, das aus 15 CDU-Parteimitgliedern aus Südbaden, Südwürttemberg und Hohenzollern bestand, ins Leben gerufen $^{71}$, er selbst bekleidete den Vorsitz. Großschwaben sollte eine Föderation von kantonal gegliederten Regionen sein (Karlsruhe, Freiburg, Stuttgart und Reutlingen), die Einbeziehung fränkischer Teile im Norden zog man zwar in Betracht, aber das Hauptaugenmerk lag auf der Eingliederung von Bayerisch-Schwaben. Fürst Erich war eventuell neben Franz Weiß Gründungsmitglied der CDU Württemberg-Hohenzollern gewesen $^{72}$; spätestens ab 1947 ist seine Parteizugehörigkeit nachgewiesen, wenngleich es manchen Reibungspunkt mit der Partei gab. Von Interesse ist jedoch die Tatsache, daß er CDU-Mitglieder in einem Komitee zur Neugliederung Südwestdeutschlands im schwäbisch-alemannischen Sinne versammeln konnte. Sein Einfluß - auch als Großgrundbesitzer - auf die oberschwäbischen CDU-Mitglieder darf nicht unterschätzt werden. Der Fürst hatte in einem Triumvirat, das Franz Weiß, Oskar Farny und Bernhard Bauknecht bildeten, in der CDU mächtige Gegenspieler, die Ende der vierziger Jahre ein Engagement des Fürsten auf Landesebene, und damit auch das Einfließen seiner Neugliederungspläne in die CDU, zu verhindern wußten. Der vorhandene Dissens lag auch in der differenzierten Einschätzung der staatlichen Zukunft Südwestdeutschlands begründet. An der Südweststaatsfrage sollte Fürst Erich mit der CDU brechen und seinen Parteiaustritt beantragen. „Ich kann dem Länderkram nicht die Bedeutung zumessen, die ihm von den Parteien zugedacht wird“, schrieb er im Sommer 1951 an den Wangener Bezirksnotar Abt: „Meine Heimat ist Schwaben. "73 Nach der Gründung der Bundesrepu-

68 "Besprechung mit dem Herrn General-Gouverneur Widmer am 12. Dezember 1947 in Wangen“, Farny an Kiechle vom 15. 1. 1948; KA RV NL Münch 44.2.

${ }^{69}$ Sowohl Südstaat als auch autonomer schwäbisch-alemannischer Staat schieden nach Farnys Dafürhalten aus.

70 „Besprechung“; KA RV NL Münch 44.2.

${ }^{71}$ Die Namen der Mitglieder des Komitees sind in den Unterlagen, die der französische Konsul Pierre d'Huart nach Tübingen verschickte, nicht aufgeführt. Zu den Zielsetzungen des Komitees und den weiteren Planungen des Fürsten Erich vgl. Kapitel II/2.

72 Sein Sohn Graf Alois von Waldburg-Zeil teilte dem Tübinger Politikwissenschaftler Andreas Dornheim mit, über Ein- und Austritt des Vaters keine Unterlagen zu besitzen; Dornheim, Adel, S. 370 .

${ }^{73}$ Erich Fürst von Waldburg-Zeil an Bezirksnotar Abt vom 4. 7. 1951; KA RV NL Münch 90.4. 
blik Deutschland glaubte der Fürst einen zu liberalen Kurs der CDU ausmachen zu können, seine weitere Mitarbeit hielt er deshalb für überflüssig und beantragte kurz vor den Kreistagswahlen 1951 die Streichung aus der Liste der CDU-Mitglieder ${ }^{74}$.

Ob sich im Kreis der autonomistischen CDU-Mitglieder um Fürst Erich auch der Ravensburger Oberbürgermeister Dr. Albert Sauer ${ }^{75}$ befunden hat, ist ungewiß, aber nicht unwahrscheinlich. Als Kultusminister war Sauer seit 12. Dezember 1946 in der „Provisorischen Regierung" Carlo Schmids tätig. Inbrünstig liebte Sauer seine oberschwäbische Heimat und hielt jede Form des Zentralismus für gefährlich - auch wenn dieser nicht von Berlin, sondern von Stuttgart ausging. Am Pfingstsamstag 1949 gehörte Sauer jedenfalls zu den Unterzeichnern der Überlinger Resolution, die nach einer Volksabstimmung über den Südweststaat die Einsetzung einer landsmannschaftlich paritätisch besetzten verfassunggebenden Landesversammlung empfahl 76 . Die in Überlingen tagenden oberschwäbischen und südbadischen CDU-Vertreter hofften durch diesen Vorschlag, das bevölkerungsmäßige Übergewicht von Nordwürttemberg und Nordbaden brechen zu können. Als sich der Südweststaat nach der Probeabstimmung 1950 deutlich abzuzeichnen begann, hegte Sauer den Verdacht, daß das katholische Oberschwaben zuungunsten des überwiegend protestantischen Altwürttemberg ins Hintertreffen gelangen könnte. Die französische Besatzungsmacht vermutete überdies, daß Sauer und andere hinter der 1948 vom Großbottwarer Ingenieur Adolf Mühleisen ins Leben gerufenen „Partei der Schwaben“, deren autonomistisch-regionalistische Forderungen ins Auge stachen, steckte ${ }^{77}$. Als erfahrener Kommunalpolitiker regte Sauer 1951 die Schaffung eines „Oberschwäbischen Städtebundes“ an ${ }^{78}$, damit eine Benachteiligung des Südostens im projektierten neuen Bundesland nicht Wirklichkeit würde. In der unmittelbaren Nachkriegszeit bleibt Sauers Einstellung mangels schriftlicher Quellen über weite Strecken unklar, sein Regionalismus und Katholizismus prädestinierten ihn nichtsdesto-

${ }^{4}$ Erich Fürst von Waldburg-Zeil an Josef Lutz (Vorstand der CDU-Ortsgruppe Leutkirch) vom 9. 10. 1951; KA RV NL Münch 90.4.

75 Albert Sauer (1902-1981), Gymnasium in Ravensburg; 1921-25 Studium der Rechtswissenschaften in Tübingen und Kiel; 1925 Promotion; 1928 Assessorexamen; Rechtsanwalt in Ravensburg; Mitglied des Windthorstbundes; 1931 Organisator der "Arbeitsgemeinschaft der Zentrumsjugend Oberschwabens“; 1932-33 MdL Württemberg (Zentrum); 1941-45 Wehrdienst; 1944 Verbindungen zum Widerstand (Eugen Bolz); 1945-46 Kriegsgefangenschaft; 1946-66 Oberbürgermeister von Ravensburg; 1946-52 MdL Württemberg-Hohenzollern (CDU); 1946-52 Landesdirektor/Minister für Kultus, Erziehung und Kunst; 1949-52 Mitglied des Bundesrates (Präsident der Ständigen Konferenz der Kultusminister); 1952-56 MdL Baden-Württemberg (CDU); Mitbegründer und Mitglied des Internationalen Büros sowie Vizepräsident der Deutschen Sektion des Rates der Gemeinden Europas; Deutscher Delegierter zur 1. bis 4. Europäischen Gemeindekonferenz des Europarates in Straßburg; seit 1960 Ehrensenator der Universität Tübingen. Vgl. auch Munzinger-Archiv 1981 - Lieferung 40/81-P-1112.

${ }^{76}$ Konstanzer, Entstehung, S. 168.

77 Pène an François-Poncet vom 13. 9. 1950; AdO Bade AP c. 2157/3 d. 44. Zur „Partei der Schwaben" vgl. Kapitel II/1.

${ }^{78}$ Sauer an Ministerialrat a. D. Eugen Hagel (Stuttgart) vom 22. 10.1951; StadtA RV NL Sauer N I 1448. Eugen Hagel (1884-1953) selbst war gebürtiger Ravensburger und hatte eine „lockere“ Vereinigung „Ravensburger Landsleute“ nach dem Krieg ins Leben gerufen. Der Stuttgarter Ministerialrat a. D., der von 1929-1932 als Vertreter der Volksrechtspartei im Württembergischen Landtag saß, trat auch gegenüber Sauer als Förderer und Verfechter des Regionalbewußtseins auf; Hagel an Sauer vom 15. 10. 1951; StadtA RV NL Sauer N I/448. 
trotz zu einem Befürworter einer konfessionell untermauerten Südstaats- bzw. Stammesstaatslösung.

Vor allem wirtschaftliche Bedenken hatte der Rottweiler Rechtsanwalt und spätere Staatspräsident von Württemberg-Hohenzollern, Lorenz Bock ${ }^{79}$, gegenüber einem aus dem französisch besetzten Südwestdeutschland geformten Südstaat, der allgemein als Vorstufe eines schwäbisch-alemannischen Stammesstaates erachtet wurde. Mit dem Rottweiler Bürgermeister und Hauptaktivisten des "Schwäbisch-Alemannischen Heimatbundes" in Württemberg-Hohenzollern, Franz Mederle, pflegte Lorenz Bock regelmäßigen Umgang. Da beide Politiker Nachbarn waren, wurde der spätere Staatspräsident in allen Belangen und Aktivitäten auf dem laufenden gehalten ${ }^{80}$. Eine belegbare Unterstützung erhielt Mederle nicht, das Interesse Bocks für Autonomiepläne war aber zweifelsohne vorhanden. Die Rekonstruktion seiner Position auch in der Frage der staatlichen Neugliederung ist nicht leicht möglich, da der Nachlaß als verschollen gelten muß ${ }^{81}$. An seiner föderalistischen Haltung konnte indes kein Zweifel bestehen: Das Schwergewicht der politischen Hoheitsrechte wollte er als Staatspräsident von Württemberg-Hohenzollern den deutschen Ländern überlassen, dem Bundesstaat gedachte er nur Zuständigkeiten einzuräumen, die im gesamtdeutschen Interesse „absolut notwendig" waren ${ }^{82}$. Im Hause Bock hielt sich wohl um die Jahreswende 1946/47 für mehrere Wochen der CSU-Politiker Josef Müller ${ }^{33}$ („Ochsensepp“) auf, nicht zuletzt um gegen die Aktivitäten des „Schwäbisch-Alemannischen Heimatbundes“ bei Bock zu intrigieren $^{84}$. Beide kannten sich über den Rottenburger Bischof Johannes Baptista Sproll ${ }^{85}$,

${ }^{79}$ Lorenz Bock (1883-1948), Gymnasium in Horb und Rottweil; 1902-07 Studium der Rechtswissenschaften in München und Tübingen; Engagement in der katholischen, nichtfarbentragenden Studentenverbindung „Alamannia“ Tübingen im Kartellverband; Referendar (Amtsgericht

Riedlingen/Donau, Landgericht Ravensburg, Staatsanwaltschaft Stuttgart); vor 1914 Rechtsanwalt in Rottweil; Mitglied des Zentrums; 1915-18 Kriegsteilnahme; 1919-33 Gemeinderat in Rottweil; 1919 Mitglied der Verfassunggebenden Landesversammlung des Freien Volksstaates Württemberg; 1919-33 MdL Württemberg (Zentrum); 1928 Fraktionsvorsitzender des Zentrums im Landtag; 1944 Verhaftung durch die Gestapo; 1947-48 Staatspräsident von Württemberg-Hohenzollern. Vgl. Bradler, Bock, S. $79 \mathrm{f}$.

${ }^{80} \mathrm{Vgl}$. dazu in diesem Kapitel „Schwäbisch-Alemannische Volkspartei“.

${ }^{81}$ Im Stadtarchiv Rottweil werden neben der Ernennungsurkunde zum Staatspräsidenten Württemberg-Hohenzollerns einige Bücher aus der Bibliothek Bocks aufbewahrt. Der Nachlaß selbst darf als verschollen gelten.

${ }^{82}$ Schwäbisches Tagblatt vom 5. 1. 1948.

${ }^{83}$ Josef Müller (1898-1979), vor 1933 in der BVP tätig; juristischer Berater kirchlicher Institutionen; 1939 Abteilung „Abwehr“ des OKW; 1943 Verhaftung; 1945 Mitbegründer der CSU; 194549 Landesvorsitzender der CSU; 1947-49 bayerischer Justizminister und Stellvertretender Ministerpräsident; 1950-52 erneut Justizminister.

An "Donaukonföderationspläne“ erinnerte sich Müller bei der Abfassung seiner Memoiren. Er vertrat die Ansicht, daß sich französische Offiziere in Lindau und Innsbruck an den Planspielen beteiligt hätten; Müller, Konsequenz, S. 326 f. In Innsbruck jedenfalls hielt sich seit Ende 1946, nach seiner Abberufung aus Vorarlberg, der ehemalige Bregenzer Bezirksdelegierte Benité auf, der 1945 die Alpenlandpläne Dietrichs unterstützt hatte (vgl. Kapitel III/1). Daß er sich allerdings weiterhin offensiv für eine alpine Union eingesetzt hat, ist unwahrscheinlich, da er den Unwillen seiner Vorgesetzten in Paris, Wien und Innsbruck bereits auf sich gezogen hatte.

${ }^{84}$ Interview mit Willi Ernst jun., einem Nachbarn von Bock in Rottweil, vom 30. 6. 1994; StadtA KN Cc 775 a.

${ }^{85}$ Im Diözesanarchiv Rottenburg waren weder im Nachlaß von Bischof Sproll (DAR N 27) noch im Nachlaß des Generalvikars Dr. Max Kottmann (DAR N 31) Spuren der Neugliederungsdis- 
der wohl den Kontakt vermittelt hat. Doch die gewaltigen Probleme Württemberg-Hohenzollerns belasteten den kranken Staatspräsidenten Bock seit Ende 1947 zusehends; am 4. August 1948 verstarb er in Tübingen, sein Freund Josef Müller hielt die Grabrede.

Auch Bocks Nachfolger, der zweite Staatspräsident von Württemberg-Hohenzollern und nachmalige Ministerpräsident von Baden-Württemberg, Dr. Gebhard Müller ${ }^{86}$, hat kaum Schriftliches zur Frage der südwestdeutschen Autonomie und seiner Haltung zu einer stammesstaatlichen Lösung der territorialen Verhältnisse hinterlassen. Gegenüber den Plänen des oberschwäbischen Adels, Österreich in eine süddeutsche Föderation einzubeziehen, verhielt sich Müller reserviert. 1949 gab er Widmer zu verstehen, daß er solche Meldungen für Zeitungsenten hielt ${ }^{87}$. In einer knappen Rezension für die Deutsche Rechts-Zeitschrift hatte Gebhard Müller 1947 auf den besonderen Wert der SchwäbischAlemannischen Demokratie für die Rechtskultur im Südwesten verwiesen, indem er den „bodenständigen“ Aspekt hervorhob ${ }^{88}$. Auf die autonomistischen Forderungen Fegers ließ er sich nicht ein, referierend gab er nur die Position des Autors wieder. Die Wortwahl Müllers verrät seinen Standpunkt: Deutschland bestand für ihn staatsrechtlich weiter $^{89}$, einer Autonomie konnte er nicht das Wort reden.

Gebhard Müller hatte sich Mitte 1948 dienstlich erneut mit der Idee einer schwäbischalemannischen Demokratie auseinanderzusetzen. Am 1. Juli 1948 händigten nämlich die Militärgouverneure den Länderchefs - darunter Lorenz Bock und Leo Wohleb - die drei „Frankfurter Dokumente“ aus, durch welche die Länder ermächtigt wurden, unter den gegebenen Bedingungen das Verfahren zur Staatsgründung auf föderativer Basis in Gang zu setzen ${ }^{90}$. Den Länderchefs oblag es nun, bis spätestens 1 . September 1948 eine verfassunggebende Versammlung einzuberufen (Dokument 1), die durch Vertreter der Länderparlamente zu beschicken wäre. Zwecks Kompetenzabgrenzung zwischen zukünftiger deutscher Regierung und den Besatzungsmächten sollte die Annahme eines Besat-

kussion der unmittelbaren Nachkriegsjahre zu finden. Auch der Zettelkasten des Bischofs (DAR N 27 ZK A-J und K-Z) barg keine Hinweise auf Verbindungen zu den Protagonisten oder auf die Rezeption dieser politischen Vorstellungen im bischöflichen Ordinariat.

${ }^{86}$ Gebhard Müller (1900-1990), aus oberschwäbischer, katholischer Lehrerfamilie stammend, 1915-18 humanistisches Gymnasium in Rottweil; 1918 Notabitur; Einrücken in ein königlich württembergisches Feldartillerieregiment in der Ludwigsburger Garnison; 1919-22 Studium der Katholischen Theologie, Geschichte und Philosophie in Tübingen und Berlin; 1922 Wechsel der Studienfächer: Volkswirtschaft und Rechtswissenschaften; 1929 Promotion; 1930-33 Referent für Steuer- und Verwaltungssachen beim Diözesanverwaltungsrat in Rottenburg am Neckar; 1931-33 Leiter des Zentrums im Stadt- und Oberamtsbezirk Rottenburg; 1934-45 Amts- und Landgerichtsrat in Göppingen, Waiblingen und Stuttgart; 1940 und 1944-45 Kriegsdienst; 194546 Oberstaatsanwalt in Stuttgart, dann Leiter der Stuttgarter Justizdelegation in Tübingen; 1946 Landesdirektor der Justiz in Württemberg-Hohenzollern; 1948-52 Staatspräsident von Württemberg-Hohenzollern; 1953-58 Ministerpräsident von Baden-Württemberg; 1959-71 Präsident des Bundesverfassungsgerichts. Vgl. Ausgewählte Dokumente, 1990, S. 45-52.

${ }^{87}$ Müller in einem Gespräch mit Widmer; „Aktenvermerk über die Besprechung bei Gouverneur Widmer am 15.7. 1949, 17.30 Uhr"; HStAS Q 1/35 Serie I 18.

${ }^{88}$ G. M[üller], Demokratie.

89 "Politisch verficht Verf., ausgehend von der historischen Schuld Preußens an dem Niedergang des Deutschen Reiches, die Bildung eines selbständigen Staates im schwäbisch-alemannischen Raume nach dem Muster der Schweiz unter Loslösung vom Reiche, das er mit dem Zusammenbruch des Jahres 1945 staatsrechtlich als erledigt und als einen Landkomplex ohne eigene politische Organisation auffaßt"; ebenda.

90 Erdmann, Ende, S. 296. 
zungsstatuts beraten werden (Dokument 3). Außerdem hießen die Militärgouverneure die deutschen Regierungschefs, Vorschläge über etwaige Änderungen der Ländergrenzen innerhalb der Westzonen vorzulegen (Dokument 2).

Die Ministerpräsidenten berieten sodann vom 8. bis 10. Juli 1948 auf dem Rittersturz bei Koblenz $z^{91}$ und am 21. und 22. Juli 1948 in Rüdesheim im Jagdschloß Niederwald ${ }^{92}$. Neben Staatspräsident Bock nahm an der Konferenz in Schloß Niederwald auch Gebhard Müller teil. In den beiden Verhandlungen wurden Vorschläge für die Neugliederung Südwestdeutschlands vorgebracht, die in der Drucksache Nr. 21 Anfang August in die Büros der Länderchefs gelangten ${ }^{93}$. Mit den darin gemachten, auf den Konferenzen auf dem Rittersturz und in Jagdschloß Niederwald eingebrachten Neugliederungsvorschlägen mußte sich alsbald ein „Ausschuß zur Überprüfung der Ländergrenzen“ beschäftigen.

Wie sahen aber die Neugliederungskonzepte aus, an denen auf badischer Seite Paul Zürcher und auf württemberg-hohenzollerischer Seite Viktor Renner und Theodor Eschenburg mitgearbeitet hatten? Für den deutschen Südwesten brachten die Ministerpräsidenten sieben Lösungsvorschläge zur Sprache. Der restaurative erste Plan sah eine Wiederherstellung der alten Länder Baden und Württemberg bei paralleler Eingliederung Hohenzollerns in eines der beiden Länder vor. Der Südweststaat wurde als zweiter Lösungsansatz vorgeschlagen. Die kleine Lösung (Württemberg-Baden und Württemberg-Hohenzollern) mit implizierter Magnettheorie bildete den nächsten Entwurf. Die Schaffung des Südstaates (Baden und Württemberg-Hohenzollern) mit der Option zum späteren Zusammenschluß mit Württemberg-Baden war als eine weitere Variante gedacht. Die nächsten beiden Vorschläge griffen die Idee einer Angliederung der Pfalz an Baden oder an einen Südweststaat auf. Als siebter und letzter Lösungsvorschlag wurde schließlich die Bildung eines "Schwäbisch-Alemannischen Staates" nach den Plänen Otto Fegers erörtert. Unter diesem Neugliederungsplan verstanden die Ministerpräsidenten die „Zusammenfassung der Länder Württemberg-Baden, Württemberg-Hohenzollern, Baden (ausdrücklich beschränkt auf den alemannischen Staat des alten Badens), des bayrischen Regierungsbezirks Schwaben und des Kreises Lindau“94. Die Tatsache, daß Fegers Pläne Mitte 1948 auf den Ministerpräsidenten-Konferenzen zumindest auf der Tagesordnung erschienen und im „Ausschuß zur Überprüfung der Ländergrenzen“ beraten wurden, widerlegt unmißverständlich die bisher in der Forschung vertretene Auffassung von der Bedeutungslosigkeit und Marginalität des Vorschlags.

Die CDU Württemberg-Hohenzollern war in ihrer Grundkonzeption mit Vorrang auf die Wiederherstellung der staatlichen Einheit Württembergs ausgerichtet. Als einzige ernstzunehmende Alternative galt die Bildung des Südweststaates. CDU-Politiker wie Fürst Erich von Waldburg-Zeil, die dank ihrer ökonomischen Macht über großen Einfluß in Oberschwaben verfügten, konnten sich innerhalb der christlich-konservativen Partei mit ihren Plänen einer stammesmäßigen Gliederung des schwäbisch-alemannischen Raumes nicht durchsetzen, wenngleich die Vorstellungen mitsamt darüber hinausgehenden Plänen einer Ausrichtung nach Wien in konservativen Kreisen und Zirkeln

${ }^{11}$ Für das Konferenzprotokoll vgl. Der Parlamentarische Rat, S. 60-142.

92 Für das Konferenzprotokoll vgl. Der Parlamentarische Rat, S. 172-270.

${ }^{93}$ Drucksache Nr. 21 vom 4. 8. 1948 „Überprüfung der Ländergrenzen/Materialsammlung“;

BA Z 12/67; außerdem als fehlerhafte Abschrift in den Akten der Stuttgarter Staatskanzlei:

HStAS EA 1/920 P32 621. Publiziert in: Der Parlamentarische Rat, S. 312-315.

${ }^{94}$ Dokument Nr. 21 "Anlage“, ebenda. 
mit Blick auf die vorderösterreichische Zeit permanent diskutiert wurden. Insgesamt zwar entschieden föderalistisch geprägt, blieb die CDU in Württemberg-Hohenzollern eine in nationalen Kategorien denkende Partei, die sich über weite Strecken als immun gegenüber autonomistischen Tendenzen zeigte.

\section{Die SPB in Baden und die SPD in Württemberg-Hobenzollern}

Auch innerhalb der badischen Sozialdemokratie - der Sozialistischen Partei in Baden (SPB) - tauchte nach 1945 keineswegs nur das von der Gruppe um Philipp Martzloff ${ }^{95}$ kreierte Konzept einer vereinigten Arbeiterpartei ${ }^{96}$ auf, das als Integrationsangebot an die Kommunisten gedacht war. Martzloffs Vorstellungen gingen in diesem Punkt nicht konform mit den Plänen des Parteivorstands in Hannover: Kurt Schumacher wies eine Vereinigung von Sozialdemokraten und Kommunisten entschieden zurück. Die zweite Gruppierung innerhalb der Sozialistischen Partei Badens um den späteren Wirtschaftsminister Friedrich Leibbrandt ${ }^{97}$, der seit Februar 1946 gemeinsam mit Martzloff den Vorsitz der Partei innehatte, machte den Föderalismus zum Ausgangspunkt ihrer Denkmodelle.

Leibbrandt selbst hatte sich 1945 in Freiburg bereits als Gründungsmitglied der „Vereinigung Abendland“ hervorgetan. Zusammen mit seinen Anhängern, die noch 1947 nach vorsichtigen Schätzungen mindestens ein Drittel der Parteimitglieder ausmachten $^{98}$, vertrat er eine eigenständige, von abendländisch-föderalistischen Gedanken inspirierte Parteipolitik. Die Unabhängigkeit gegenüber einer SPD-Parteizentrale war oberstes Prinzip für Leibbrandts Parteiführung, was im Parteinamen „Sozialistische Partei/ Land Baden“ zum Ausdruck kam. 1945 erwartete er die Entstehung einer „Republik Baden“, die an Frankreich angelehnt ihren Weg in die Zukunft gehen sollte ${ }^{99}$. „Als letztes

${ }^{5}$ Philipp Martzloff (1880-1962), 1894-97 Schneiderlehre in Freiburg i. Br.; 1898 Beitritt zur SPD; 1900-33 Arbeitersekretär bei den freien Gewerkschaften; 1908-1933 SPD-Vorsitzender in Freiburg; 1914-33 Stadtverordneter; 1918-19 Mitglied der Badischen Vorläufigen Volksregierung; 1919-21 und 1925-33 Mitglied der Badischen Verfassunggebenden Nationalversammlung/MdL Baden (SPD); 1933-34 politische Verfolgung und Inhaftierung im KZ Ankenbuk; 1944 KZ Dachau; 1945-46 Mitbegründer der Sozialistischen Partei in Baden; 1946-52 Ministerialdirektor im Landesarbeitsamt; 1947-52 MdL Baden; 1948-52 Erster Landtagsvizepräsident. Vgl. dazu weiter: Clasen, Martzloff und Brandt/Rürup, Volksbewegung, S. 165.

${ }^{6}$ Zur Problematik der Vereinigung von Sozialdemokraten und Kommunisten: Goguel, Dokumente; Bittel, Bewegung; Müller, Antifa-Ausschüsse; Müller, Jahr.

${ }^{97}$ Friedrich Leibbrandt (1894-1960), Besuch der Oberrealschule in Karlsruhe; Studium der Naturwissenschaften in Frankreich und Deutschland; Examen als „Ingénieur Chimiste“; Promotion im Fach Chemie in Freiburg i. Br.; daselbst Assistent am Chemischen Institut, später Leiter einer chemischen Fabrik; 1933-45 durch die Gestapo verfolgt, Aufenthalt in Frankreich; nach 1945 Präsident der Industrie- und Handelskammer in Freiburg; 1946 Mitglied der Kreisversammlung (SPB); 1946-48 Staatssekretär, dann Minister für Wirtschaft und Arbeit; 1947-52 MdL Baden. Vgl. auch Wolfrum, Besatzungspolitik, S. 285 und Rößler, Landtag, S. 125.

${ }^{98}$ SP activité générale 1947/49; AdO Bade c. 2151. Zitiert nach Wolfrum, Besatzungspolitik, S. 285. Auch der Freiburger Oberdelegierte Pène äußerte auf der Sitzung des CGAAA vom 13. 1. 1947 die Auffassung, daß der föderalistische Flügel in der SP in der Minorität sei; MAE Y-Int. 19441949654.

99 Wolfrum, Besatzungspolitik, S. 285. Keineswegs waren die Unterschiede der Föderalismusvorstellungen zwischen Sozialisten und christlich-konservativen Kreisen so groß, wie Edgar Wolfrum glauben machen will. Er täuscht sich, wenn er die Überwindung der engstirnigen „Nationalismen“ durch ein zukünftiges Europa nur den Sozialisten attestiert, den christlich-konservativen 
Ziel gilt für die Sozialisten Badens die Bildung der Vereinigten Staaten von Europa, wobei es belanglos bleibt, ob das Land Baden als solches oder im Rahmen einer föderalistischen Bindung mit den anderen süddeutschen Staaten eingeht. "100 Es ist müßig, darüber zu spekulieren, ob Leibbrandt mit einer „föderalistischen Bindung“ der süddeutschen Staaten auf eine Art Donaukonföderation - respektive alpine Union - angespielt hat, sicher ist jedenfalls, daß er über den Kontakt zu Josef Ruby und der „Vereinigung Abendland“ mit den Zielsetzungen der Alpenlandbewegung vertraut war. In Leibbrandts politischen Konzeptionen kam zuerst die Bildung Europas, dessen Bausteine die deutschen Länder sein mußten; einen föderativen Aufbau Gesamtdeutschlands sah sein Konzept nicht vor. Unverkennbar standen hinter Leibbrandts Gedanken die Europa-Konföderationspläne der französischen Sozialisten ${ }^{101}$, zu denen er herzliche und intensive Kontakte pflegte.

In der Erstausgabe der Parteizeitung Das Volk, die zur Jahresmitte 1946 erschien, konkretisierte Friedrich Leibbrandt seine politischen Vorstellungen und erteilte seinen zuvor geäußerten Badenplänen eine indirekte Abfuhr: Die Föderierung Europas müsse den Vorrang vor der Restauration der Nationalstaaten haben, wofür die Sozialisten Badens auch Dinge opfern würden, die ihnen einmal teuer waren - sprich den deutschen Nationalstaat ${ }^{102}$. Für Leibbrandt war es unerheblich, ob nun der französisch besetzte Teil Badens oder ein Zusammenschluß der Südzone in Form des Südstaates in einem konföderierten Europa aufging ${ }^{103}$. „Wir [die $\left.S P B\right]$ würden auf Grund wirtschaftlicher und politischer Erwägungen einen engeren Zusammenschlu $\beta$ des badischen und des württembergischen Gebietes innerhalb der französischen Zone begrüßen", hob Leibbrandt hervor und argumentierte mit der ethnischen Homogenität eines Südstaates. „Alemannen und Sueben sind gleiche germanische Völkerschaften [...]. Es ist daher folgerichtig, wenn der Wunsch nach der Bildung einer Einheit aus wirtschaftlichen und etnographischen [sic!] Gründen mit Beharrlichkeit verfolgt wird. "104 Die von Leibbrandt vertretene föderalistische Nachkriegsordnung wies die Konturen eines dezentralen Europas - des Abendlandes - auf. In der Einschätzung des „Schwäbisch-Alemannischen Heimatbundes“ fällte Friedrich Leibbrandt ein dezidiertes Urteil: „Der vom Heimatbund propagierte schwäbisch-alemannische Staat ist eine Utopie; aber man kann von der Bewegung dadurch profitieren, daß man zur Schaffung eines aus Südbaden und Südwürttemberg bestehenden Staat[es] gelangt. "105 Skepsis legte Leibbrandt bezüglich eines stammesföderalistisch organisierten, autonomen Südwestdeutschlands an den Tag. Aufgrund der politischen Realitäten befürwortete er gleichwohl die Schaffung eines Südstaates lebhaft, allerdings nicht, um ihn in einen deutschen Bundesstaat, sondern unmittelbar in eine europäische Konföderation einzubringen.

Föderalisten aber einen „zeittypischen Rückzug auf die Provinz“ vorwirft. Gerade die weitgehenden Föderalismus- und Autonomievorstellungen standen auf der Grundlage eines konföderierten Europas, das bisweilen in den Begriff „Abendland“ gekleidet wurde.

100 Bericht Leibbrandts vom 24. 12. 1945 über die Besprechung mit Vertretern der Militärregierung vom 22. 12. 1945; AdO Bade c. 2151.

101 Vgl. Lipgens, Europa-Föderationspläne und Ders., Anfänge.

${ }^{102}$ Friedrich Leibbrandt: Europa - ein Ziel, in: Das Volk vom 3. 7. 1946 [Erstausgabe].

${ }^{103}$ Wolfrum, Besatzungspolitik, S. 288.

104 Ebenda.

${ }^{105}$ Befragung Leibbrandts zum Thema „Heimatbund“ [o. D.]; AdO Bade Con. Fribourg c. 2177/2. 
Europäische Konföderationsgedanken, die von Teilen der badischen Sozialisten propagiert wurden, fanden bei der unter dem Namen SPD ${ }^{106}$ wiedergegründeten Sozialdemokratie in Württemberg-Hohenzollern nur geringen Anklang. Carlo Schmid, der föderalistische Hoffnungsträger der Franzosen und Gegenspieler Kurt Schumachers im Südwesten, konnte seinem badischen Pendant Leibbrandt soweit nicht folgen. Als führender politischer Vertreter im Süden Württembergs arbeitete er zusammen mit anderen Sozialdemokraten auf die Wiedervereinigung beider Landesteile hin. In einem ausführlichen Gutachten mit dem Titel Das Land Wïrttemberg (Schwaben) als geistige und wirtschaftliche Einheit wurde Carlo Schmid von einem politischen Gesinnungsgenossen, dem Regierungsdirektor und ehemaligen Direktor des Reichsamtes für Wirtschaftsausbau - Abteilung Stuttgart - Schumacher, bereits im Juli 1945 geradezu beschworen, die Einheit Württembergs zu retten ${ }^{107}$. Doch hinter der Forderung verbarg sich ein weitreichendes Neugliederungsprogramm: Württemberg (d. i. Schwaben) sollte sich im Westen entlang der Linie Mainz-Mannheim-Säckingen und im Süden vom Oberrhein über den Bodensee bis Bregenz erstrecken. Im Osten gab Schumacher als Grenze die Städte Kempten, Nördlingen und Kitzingen an, im Norden schlug er den Main vor: ein schwäbischer Staat, der territorial über den Zusammenschluß von Baden und Württemberg weit hinausgehen sollte und im Norden fränkisch besiedelte Gebiete mit eingeschlossen hätte. „Die Grenzen Württembergs müssen seinen wirtschaftlichen, geistigen und politischen Aufgaben entsprechen", erklärte Schumacher und forderte statt der momentanen Teilung eine Ergänzung „mit direktem Anschluß Württembergs an die Schweiz, Österreich und Italien" ${ }^{108}$. Schwaben hätte nach Schumacher somit aus den Ländern Baden und Württemberg sowie aus Teilen von Südhessen und dem österreichischen Vorarlberg bestehen sollen. Nur der bayerische Regierungsbezirk Schwaben blieb bei Schumachers Planung außen vor. Über den weiteren Aufbau Mitteleuropas ließ sich der Stuttgarter Regierungsdirektor nicht aus, von föderalistischen Überlegungen finden sich in der Ausarbeitung keine Spuren.

Im Gegensatz zur offiziellen Parteidoktrin vertrat Carlo Schmid 1945/46 weitreichende föderalistische Positionen ${ }^{109}$, die jedoch rasch der Vergessenheit anheimgefallen sind $^{110}$. Auf dem ersten Landesparteitag der SPD Württemberg-Hohenzollern führte Carlo Schmid am 10. Februar 1946 in Reutlingen in seinem Referat Weg und Ziel der So-

${ }^{106}$ Die französische Besatzungsmacht erlaubte in Württemberg-Hohenzollern das Führen des Buchstabens D im Parteinamen, wohl auch, weil an diesem Territorium französischerseits kein adäquates Interesse bestand. Zu den französischen Wünschen, Württemberg-Hohenzollern mit den Amerikanern zu tauschen, vgl. Kapitel I/3.

${ }^{107}$ Dr. Schumacher: Das Land Württemberg (Schwaben) als geistige und wirtschaftliche Einheit (masch. 5 S.) vom 12. 7. 1945; AsD NL Schmid 1151.

108 Ebenda, S. 4.

${ }^{109}$ Angeblich habe Schmid versucht, 1945 eine „Parti unitaire de l'Allemagne du Sud" zu gründen, was aber von der französischen Besatzungsmacht verboten worden sei; Roux, Problèmes, S. 42. Im AdO in Colmar konnte der Verfasser keine Hinweise auf einen solchen Parteigründungsversuch durch Carlo Schmid finden, die mangelnde Erschließung der württemberg-hohenzollerischen Bestände schließt aber das Vorhandensein von Material keineswegs aus.

${ }^{110} \mathrm{Am}$ bemerkenswertesten sei der Wandel der Gesinnung in Württemberg-Hohenzollern bei Carlo Schmid zu beobachten gewesen, erläuterte der Tübinger Oberdelegierte Widmer dem CGAAA in Paris am 13. 1. 1947; habe Schmid doch 1945 einen schwachen Staatenbund empfohlen, so plädiere er jetzt für einen starken Bundesstaat „einschließlich eines über die Polizei verfügenden Innenministers"; MAE Y-Int. 1944-1949 654. 
zialdemokratie 111 auch einige seiner Vorstellungen über den staatlichen Aufbau Deutschlands aus, die mit dem Begriff „Verschweizerung " 112 treffend umschrieben sind. Deutschland sollte als „schwacher“ Bundesstaat - oder als „starke“ Konföderation nach dem Vorbild der Schweiz staatsrechtlich wiedererstehen. „Schauen wir nach Süden: nur wenige hundert Kilometer von hier liegt die Schweiz im Frieden ihrer Berge, kraftvoll und stolz seit Jahrhunderten eidgenössisch konföderiert und politisch und staatlich so einig wie irgendein zentralistischer Staat “, ließ Schmid die Genossen wissen ${ }^{113}$; und er fuhr fort: „Sollte das, was den Schweizern so gut bekommen ist, für uns Deutsche ein Schaden sein? Sollten wir nicht auf unsere Weise auch Eidgenossen werden können?" Den „Berliner Zentralismus“ verachtete Schmid, mit Berlin als Hauptstadt („mir persönlich liegt es zu nahe bei Potsdam“114) eines zukünftigen „schwachen" deutschen Bundesstaates hätte er sich nur schwerlich abfinden können; "gesunde und kräftige deutsche Länder ${ }^{\star}$ sollten dereinst das Fundament eines neuen, dezentral organisierten Bundesstaates bilden, „dessen Spitze aber nicht mehr Kompetenzen übertragen bekommen soll, als zur Bewältigung der gemeinsamen Aufgaben unbedingt erforderlich sind"115. Für Südwestdeutschland ergab sich damit eine Art Brückenfunktion nach Frankreich und in die Schweiz: „Wir hier unten im Südwesten Deutschlands fühlen uns in besonderem Maße zu unseren Nachbarn südlich und westlich des Rheins hingezogen"116; einen eigenen Neugliederungsvorschlag legte Schmid allerdings in Reutlingen nicht vor, die Restauration Württembergs als starkes und wirtschaftlich leistungsfähiges Land erfüllte sein Denken. Im übrigen verwies Schmid in der Rede explizit auf seine grundsätzliche Übereinstimmung mit den föderalistisch-partikularistischen Vorstellungen des bayerischen SPD-Ministerpräsidenten Wilhelm Hoegner ${ }^{117}$. Der Gedanke der

${ }^{111}$ Die Rede Schmids „Weg und Ziel der Sozialdemokratie“ ist in einem 1946 erschienenen Sammelband abgedruckt worden; in späteren Ausgaben wurden Teile gekürzt. Maßgeblich daher: Karl Schmid: Die Forderung des Tages. Reden und Aufsätze, Stuttgart 1946, S. 50-80.

112 Der Gedanke der „Verschweizerung“ war in Württemberg-Hohenzollern nach 1945 sehr populär. Viele Diskussionen über die innere Neuordnung orientierten sich am schweizerischen Vorbild, das in Otto Fegers Buch Schwäbisch-Alemannische Demokratie aufgezeigt war. In weiten Kreisen wurde darüber leidenschaftlich diskutiert; vgl. Auerbach, Anfänge, S. 618 Anmerkung 73. Dieser Sachverhalt wurde dem Verfasser von Otto Rundel, dem späteren persönlichen Referenten Kurt Georg Kiesingers und nachmaligen Präsidenten der Führungsakademie BadenWürttemberg in Karlsruhe, unterstrichen; er erinnerte sich insbesondere an die endlosen Diskussionen in seiner Heimatstadt Ravensburg, an denen er nach 1945 interessiert teilnahm. Rundel selbst erwarb 1946 - sofort nach dem Erscheinen - ein Exemplar der Schwäbisch-Alemannischen Demokratie; Interview mit Otto Rundel vom 24. 3. 1995; StadtA KN Cc 775 a.

113 Schmid, Forderung, S. 74.

114 Ebenda.

115 Ebenda.

116 Ebenda, S. 75.

117 Hoegner hatte in seinem Schweizer Exil am 29. 11. 1943 einen „Vorschlag für eine Neugliederung Deutschlands" zu Papier gebracht. Für die Zeit nach dem Weltkrieg lehnte er entschieden die Reorganisation eines deutschen Einheitsstaates ab. Statt dessen sollte ein föderativ aufgebautes Deutschland (Staatenbund oder Bundesstaat waren nach Hoegner möglich) entstehen, im Südwesten mit den beiden Ländern Baden und Württemberg, wobei letzterem Hohenzollern zugeschlagen werden sollte. Vgl. Hoegner, Außenseiter, S. 166-169. Zusammen mit dem ehemaligen Reichskanzler Josef Wirth und anderen engagierte sich Hoegner im Schweizer Exil in der Bewegung „Das Demokratische Deutschland“. Zu den Vorstellungen dieser Bewegung vgl.: Das Demokratische Deutschland, 1945 und Kapitel IV/2. 
„Verschweizerung“ der politischen Zustände in Deutschland bewegte ihn aber noch das ganze Jahr 1946. Auf der achten Landrätetagung in Schramberg zitierte er Anfang Juni 1946 erneut die Schweiz als leuchtendes Vorbild. Die Stärkung der Gemeinden müsse das Ziel der zukünftigen Politik sein, ein "gesunder Staat“ war in Schmids Augen nichts anderes als „eine Konföderation von Gemeinden "118. Hier erwies sich Schmids Föderalismusbegriff als elastisch genug, eine über den föderativen Staatsaufbau hinausgehende Einbeziehung des Subsidiaritätsprinzips zu gewährleisten.

Doch so sehr Schmids Gedanken von einem föderalistischen Aufbau Deutschlands durchdrungen waren, gab er sich im Falle Württembergs als Partikularist zu erkennen. Die Einheit des durch die Besatzungszonen getrennten Landes galt ihm als oberste Prämisse. Die seit Oktober 1945 in verschiedenen Städten durchgeführten Landrätetagungen dienten nicht zuletzt dem Zweck, das Bewußtsein für den württembergischen Staat wachzuhalten oder zu festigen. Angesichts der Propaganda des „Aktionskomitees des Alpenländischen demokratischen Bundes“ sah sich Carlo Schmid genötigt, auf der zweiten Landrätetagung in Wangen im Allgäu am 1. Dezember 1945 die Einheit des württembergischen Staates regelrecht zu beschwören ${ }^{119}$, da er erkannt hatte, daß der äußerste Süden Württembergs nicht immun für eine grundlegende Umgestaltung der politischen Verhältnisse war. Dem Fürsten Erich von Waldburg-Zeil, der in Wangen als Gast der Landrätetagung beiwohnte, stießen Schmids scharf-ablehnende Worte zum Thema Alpenland jedenfalls bitter auf ${ }^{120}$.

Der zweite prominente Landespolitiker der SPD Württemberg-Hohenzollern, der Reutlinger Oberbürgermeister Oskar Kalbfell121, suchte 1945 intensiv nach Möglichkeiten der föderalistischen Neugestaltung Mitteleuropas und war, im Gegensatz zu Schmid, ein Befürworter der alpenländischen Lösung. In einem persönlichen Gespräch mit Theodor Eschenburg äußerte der Reutlinger Oberbürgermeister im Dezember 1945 die Ansicht, daß er einen Zusammenschluß von Württemberg, Baden und Bayern mit Vorarlberg und Tirol für eine vernünftige Lösung hielte ${ }^{122}$. Auf die Alpenlandpläne ging

118 „Besonders in der Schweiz wird die Staatsangehörigkeit vom Gemeindebürgerrecht abhängig gemacht. Ich halte diesen Zustand für gesund und glaube, daß wir den Zentralismus, auch den Stuttgarter Zentralismus, [...] zurückschrauben und auf die Gemeinden abwälzen müssen“; Protokolle der Landrätetagungen, Schramberg 1. 6. 1946, S. 6. Schmid begab sich hier in unmittelbare Nähe zu den Vorstellungen Fegers hinsichtlich eines „Ortsbürgerrechts“.

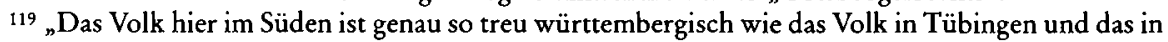
Stuttgart und das in Heilbronn"; Protokolle der Landrätetagungen, Wangen 1. 12. 1945, S. 14.

${ }^{120}$ Schmid sprach von „Klübchen ", die vom „Hohentwiel bis nach Bregenz" Beziehungen angeknüpft hätten; er sah in den Alpenlandplänen „den Zeitvertreib müßiger Leute“, von „Einzelgängern“, ohne Widerhall in der Bevölkerung; Protokolle der Landrätetagungen, Wangen 1. 12. 1945, S. 14 f. Ähnliche Bemerkungen mit Spekulationen über die mutmaßlichen französischen Hintermänner: Schmid, Erinnerungen, S. 229.

121 Oskar Kalbfell (1897-1979), 1904-11 Schule in (Reutlingen-)Betzingen; 1919 Eintritt in die SPD; 1922 Wahl in den Gemeinderat von Reutlingen; 1928 Wiederwahl, SPD-Fraktionsvorsitzender; 1930-37 Geschäftsführer der Firma Bobrzyk sen. (Baumaterialien); 1933 KZ Heuberg; 1937-47 Prokurist und Teilhaber der Firma Briel \& Kalbfell (Baustoffhandlung in Reutlingen); 1945-73 Oberbürgermeister von Reutlingen; 1945-47 Landrat des Kreises Reutlingen; 1946-52 Mitglied des Landtages von Württemberg-Hohenzollern, SPD-Fraktionsvorsitzender; 1949-53 MdB (SPD); 1952-1958 MdL Baden-Württemberg (SPD). Vgl. dazu weiter Wehling, Kalbfell.

122 Schriftliche Auskunft von Theodor Eschenburg an Andreas Dornheim vom 2. 6. 1986. Zitiert nach Dornheim, Adel, S. 379. 
Eschenburg, der diese Konzepte als reine „Hirngespinste“ einschätzte, selbstredend nicht ein, sondern er erläuterte dem Reutlinger Oberbürgermeister den Widerwillen vieler Österreicher, sich einer solchen Konföderation anzuschließen.

\section{Die DP in Baden und die DVP in Württemberg-Hobenzollern}

Die südbadische Demokratische Partei (DP) wurde in Freiburg am 20. Januar 1946 wiedergegründet. Im Anschluß an die Gründungsversammlung beantragte der Lahrer Oberbürgermeister Paul Waeldin ${ }^{123}$ bei der Militärregierung die Zulassung der Partei; Ende Mai 1946 wurde die Genehmigung erteilt. Als Erster Vorsitzender der südbadischen DP trat Waeldin als nationaler Mann der Besatzungsmacht gegenüber, indem er im Herbst 1946 versicherte, daß die DP gegen jede Form von „Separatismus und Partikularismus" eintrete und einen "schwäbisch-alemannischen Staat“ kategorisch ablehnen würde ${ }^{124}$. Deshalb richtete der Lahrer Oberbürgermeister für die Fraktion der Demokraten am 10. Dezember 1947 eine förmliche Anfrage wegen der „separatistischen“ Tendenzen des Heimatbundes an den Badischen Landtag ${ }^{125}$. Für die Demokratische Partei komme allerhöchstens, so Waeldin im Herbst 1946, ein aus Südbaden und Südwürttemberg gebildeter Südstaat in Frage, wobei die Hoffnungen der DP auf der Wiederherstellung des alten Landes Baden lägen, „das in einen deutschen Staatenbund eingeschlossen sein werde“"126. In jeder Hinsicht sollte das Endziel demokratischer Politik in der Bildung der Vereinigten Staaten von Europa [,états unis de l'Europe“] liegen. Im März 1946 hatte Waeldin bereits dem Lahrer Kreisdelegierten Rendinger seine Vorstellungen über den künftigen staatlichen Aufbau Deutschlands kundgetan ${ }^{127}$ : Nach dem Modell der Schweiz müsse Deutschland eine föderalistische Verfassung erhalten, die eine Hegemonie Preußens ausschließe. Überhaupt gab Waeldin der französischen Besatzungsmacht zu verstehen, daß ein föderalistisch aufgebautes Deutschland nur in einem „europäischen Staatenbund“ Bestand haben könne, Frankreich billigte er darin eine Führungs-

123 Paul Waeldin (1888-1969), 1894-97 Volksschule in Lahr; 1897-1906 Gymnasium in Lahr und Realgymnasium in Ettenheim; 1906-07 Militärdienst; Studium der Rechts- und Staatswissenschaften in Heidelberg; 1911 Promotion; 1912 Prokurist im väterlichen Betrieb; 1914-18 Kriegsteilnehmer; 1918 Stadtverordneter, Obmann des Bürgerausschusses und Stadtrat in Lahr; 192933 MdL Baden (DDP); 1945-52 ehrenamtlicher Bürgermeister von Lahr; 1946-47 Mitglied der Beratenden Landesversammlung; 1946-47 Staatssekretär der Finanzen des Landes Baden; 194752 MdL Baden (DP); 1952-53 Mitglied der Verfassunggebenden Landesversammlung BadenWürttemberg; 1952-57 Regierungspräsident von Südbaden. Vgl. dazu weiter Liessem-Breinlinger, Waeldin.

124 "Ce que pensent les leaders des quatre partis politiques du Heimatbund" vom 3. 9. 1946; AdO Bade Con. Fribourg c. 2177/2.

125 „Förmliche Anfrage Nr. 36 betreffend: Separatistische Tendenzen des Schwäbisch-Alemannischen Heimatbundes in Singen“, in: Verhandlungen des Badischen Landtages 15. Sitzung vom 20. 1. 1948. Die Anfrage wurde nie im Landtag behandelt, allerdings hatte Leo Wohleb bereits die schriftliche Antwort darauf parat: Die Badische Landesregierung sehe sich nicht zum Eingreifen veranlaßt; StA FR C 5/1 2749. Der Oberdelegierte Pène hielt die Anfrage für undemokratisch, ein Hinweis auf gewisse Sympathien für den Heimatbund; Pène an Wohleb vom 31. 12. 1947; ebenda.

126 Waeldin sprach ausdrücklich von einer fédération d'états allemands; AdO Bade Con. Fribourg c. $2177 / 2$.

${ }^{127}$ Rendinger an Pène vom 26. 3. 1947; AdO HCFA Cab. Civil POL-II-B p. 27. 
rolle zu. Insgesamt überwog allerdings bei Waeldin das nationale Element, seine Gedanken kreisten eher um einen deutschen Bundesstaat als um einen lockeren Staatenbund, für den Südwesten redete er einer Wiederherstellung Badens das Wort.

Doch die DP stand keinesfalls geschlossen hinter der Einschätzung ihres Ersten Vorsitzenden. Wie die politischen Verhältnisse im Markgräflerland paradigmatisch gezeigt haben ${ }^{128}$, herrschte an der Parteibasis mitunter eine andere Sicht zur staatlichen Neustrukturierung. Auch der Freiburger Oberdelegierte Pène meinte 1946 zwei etwa gleich starke Parteiflügel innerhalb der DP zu erkennen ${ }^{129}$ : den föderalistischen um den Lörracher Landrat Kraus und den zentralistischen um Waeldin. Der den Demokraten nahestehende Max Demmler, der höchstwahrscheinlich im Jahr 1946 Parteimitglied war, propagierte im Dreiländereck am heftigsten die Ziele des „Schwäbisch-Alemannischen Heimatbundes“. In seinem Engagement fand er im Bürgermeister von Weil am Rhein, Peter Hartmann, einen entschlossenen und kampfbereiten Verbündeten, der sich beim Aufbau der DP bereits einige Lorbeeren verdient hatte. Als Stellvertretender Vorsitzender des Kreisverbandes Lörrach vertrat Hartmann jedoch einen gänzlich von der Position Waeldins unterschiedenen Parteiflügel. Sein Eintreten für einen auf der Grundlage des Föderalismus im Innern gestalteten, weitgehend autonomen schwäbisch-alemannischen Staat fand Ausdruck in seiner Beteiligung an den Aktivitäten des Heimatbundes.

Auch in Württemberg-Hohenzollern wurde die DVP als demokratische Partei erst verhältnismäßig spät gegründet. Wie in Baden, reagierte die französische Besatzungsmacht mit einer Art Verhinderungstaktik auf die Genehmigungsgesuche der Demokraten. Neben zwei sozialistischen und einer konservativen Partei sah man französischerseits zuerst kein Bedürfnis nach einer vierten Kraft und glaubte, durch Hinauszögern der Lizenz die Angelegenheit obsolet machen zu können. Erst im zweiten Anlauf gelang es, mit Wirkung vom 19. Juli 1946, also vier Monate nach Zulassung der übrigen Parteien, das französische Plazet zu erhalten; die DVP Württemberg-Hohenzollern konstituierte sich am 17. August 1946 ${ }^{130}$. Die Demokraten faßten in der Folgezeit vornehmlich in den evangelischen Landkreisen Fuß, vor allem in Tübingen und Reutlingen. Das katholische Oberland blieb Terra incognita, in neun Landkreisen waren sie überhaupt nicht vertreten. Die Betonung des Nationalen, der Einsatz für Stärkung der Freiheitsrechte des eigenständigen und verantwortungsbewußt handelnden Individuums und die bürgerliche Ausprägung waren die Merkmale der DVP. Außerdem muß eine starke Ausrichtung nach der Schwesterpartei in Württemberg-Baden konstatiert werden, deren Linie von Reinhold Maier und Theodor Heuss bestimmt war. Eine Analyse der Ergebnisse der ersten Nachkriegswahlen läßt die Wählerschichten der DVP in Württemberg-Hohenzollern erkennen. Die industrialisierten, protestantischen Gebiete mit einem hohen Anteil an Selbständigen, mittleren Gewerbetreibenden und Beschäftigten des öffentlichen Dienstes waren die Hochburgen der Demokraten ${ }^{131}$. Aus diesem Milieu stammten andererseits nur sehr wenige Anhänger eines autonomen Südwestdeutschlands. Als Hauptvertreter einer extrem föderalistischen Position innerhalb der DVP in Württem-

${ }^{128}$ Zum Landschaftsverband „Markgräflerland“ des „Schwäbisch-Alemannischen Heimatbundes“ vgl. Kapitel III/4.

${ }^{129}$ Zusammenkunft des CGAAA vom 13. 1. 1947; MAE Y-Int. 1944-1949 654.

130 Sauer, Entwicklung, S. 170.

${ }^{131}$ Adam, Liberalismus, S. 225. 
berg-Hohenzollern hat der Schwenninger Oberbürgermeister und Protestant Dr. Otto Gönnenwein ${ }^{132}$ zu gelten.

„Es wird mir übel, wenn ich vom, Wiederaufbau des Reiches' höre, und ich habe auch in meinen Reden zu den Kreiswahlen gegen dieses gedankenlose Geplapper Stellung genommen, mit dem Erfolg, daß man in den eigenen demokratischen Reihen recht unzufrieden mit meiner Stellungnahme wurde“, schrieb Gönnenwein Ende Oktober 1946 an Otto Feger ${ }^{133}$ und umriß damit sein erfolgloses Bemühen, die Ausrichtung der DVP auf eine vom Föderalismus geprägte Position zu bewirken. In einer Fülle von Versammlungen zu den Wahlen im Oktober 1946 hatte Gönnenwein in Württemberg-Hohenzollern deutlich gemacht, daß das Reich nicht mehr erstehen und an seine Stelle durch Zollunion verbundene, weitgehend selbständige Länder treten würden, deren Aufbau die Selbstverwaltung der Kreise und Städte sichern werde ${ }^{134}$. Die innerparteiliche Ablehnung der Autonomieforderungen Gönnenweins ließ jenen in der Folgezeit vor einer weiteren, noch heftiger vorgetragenen Kritik des Parteikurses zurückschrecken. Doch Gönnenwein hatte auch innerparteilichen Zuspruch gefunden: Die Demokraten in Ravensburg galten als „Anhänger des Regionalismus, [und] deshalb in Opposition zu der Vorstellung einer zentralen Regierung“, ihr Antiborussianismus war notorisch"135.

Der Schwenninger Oberbürgermeister gab sich im Umgang mit der französischen Besatzungsmacht nicht zurückhaltend. Sein Ansprechpartner war der Rottweiler Kreisdelegierte Garnier-Dupré, der sich auch für die Zulassung der autonomistischen „Schwäbisch-Alemannischen Volkspartei“ verwendet hatte ${ }^{136}$. Auf Bitten Garnier-Duprés fertigte Otto Gönnenwein im Februar 1947 eine Denkschrift über die zukünftige Gliederung Deutschlands an ${ }^{137}$, in der er sich als überzeugter Anhänger einer alpinen Union respektive einer Donaukonföderation - zu erkennen gab. „Ich persönlich würde es bevorzugen, wenn die Staaten des Südens mit Österreich in einer Donaukonföderation [Confédération danubienne] vereinigt wären. Aber da eine politische Verwirklichung dieser Idee nicht möglich zu sein scheint, muß man einen Zusammenschluß der deutschen Staaten in einer Allianz in Betracht ziehen. "138 Die „Allianz" - sprich: der Staatenbund - hätte die vollkommene Gleichheit und Freiheit der einzelnen Teile auf wirtschaftlichem, kulturellem und wissenschaftlichem Gebiet zu gewähren. In den verantwortlichen Positionen sollten in den jeweiligen Ländern nur „Einheimische“ tätig sein. „Die süddeutsche Bevölkerung hat genug vom grellen Kommandoton der Preußen “139, fuhr Gönnenwein in seiner Denkschrift fort und hieb damit erneut in die von Feger und dem Heimatbund geschlagene Wunde. Das Bürgerrecht dürfe den Flüchtlingen keines-

132 Zu Gönnenweins Biographie und dessen Rezeption der Gedanken der Schwäbisch-Alemannischen Demokratie vgl. Kapitel IV/1.

${ }^{133}$ Gönnenwein an Feger vom 21. 10. 1946; StadtA KN BA A-Z 1945/47.

134 „Demokratischer Aufbau der Selbstverwaltung ${ }^{c}$, in: Rottweiler Rundschau vom 11. 10. 1946.

${ }^{135}$ Ravensburg: Rapport mensuel de janvier 1946 vom 23. 1. 1946; AdO W-H l)Ravensburg c. 3345.

${ }^{136}$ Der Rottweiler Bürgermeister Franz Mederle hatte im März 1946 die Gründung einer autonomistischen Partei angestrebt; vgl. dazu in diesem Kapitel „Schwäbisch-Alemannische Volkspartei".

137 Otto Gönnenwein: [Denkschrift über den staatlichen Aufbau Deutschlands] (masch. 6 S.) vom 17. 2. 1947; AdO W-H 1f. Ser. Div. c. 2519 p. 6.

138 Ebenda, S. 5.

139 Ebenda, S. 6. 
falls gegeben werden, ansonsten seien eine neue „Preußifizierung" und ein Aufkeimen des Zentralismus zu befürchten.

Für Südwestdeutschland berief sich Gönnenwein auf den von Otto Feger propagierten schwäbisch-alemannischen Staat, auch wenn er Zweifel an der wirtschaftlichen Lebensfähigkeit eines autonomen Alemannien deutlich machte. Trotzdem könnte ein südwestdeutscher Staat, der in einen deutschen Staatenbund eingebunden wäre, nach den Fegerschen Plänen konstituiert werden. Für Fragen der Außenpolitik, der Währung, des Zolls, der Reparationen, der Steuergesetzgebung, des Handels- und des Gemeinen Rechts wären die Kompetenzen an die obersten Organe des Staatenbundes gegangen, nämlich an das aus den "Landtagen" gewählte Parlament und den aus den jeweiligen Regierungen bestellten "Föderationsrat" ["Conseil de Fédération"] ${ }^{140}$. Den Gliedstaaten wäre nach den Plänen Gönnenweins eine gänzliche Autonomie in kulturellen und innerstaatlichen Verwaltungsbelangen verblieben. Aber selbst im Fall der Schaffung eines deutschen Staatenbundes war sich der Schwenninger Oberbürgermeister bewußt, daß dieser keine vollständige Souveränität besitzen könnte. Nach dem Rückzug der Amerikaner werde Deutschland weiterhin in zumindest drei Einflußsphären geteilt sein (Großbritannien, Frankreich und Sowjetunion), und nur die Aufnahme Deutschlands in die Vereinigten Staaten von Europa könne das Problem entwirren, „eine Lösung, die von allen vernünftigen Politikern gewünscht wird “"141, resümierte Gönnenwein in seiner Denkschrift.

Otto Gönnenwein, 1946 von der Bevölkerung als Schwenninger Oberbürgermeister bestätigt, scheiterte bei den Kommunalwahlen 1949 als Kandidat der FDP/DVP an dem SPD-Gegenkandidaten. Zwischenzeitlich war sein Habilitationsverfahren unter dem Dekanat Gustav Radbruchs an der Heidelberger Juristenfakultät im zweiten Anlauf abgeschlossen worden; Gönnenwein konnte ab 1949 den Lehrstuhl für Deutsche Rechtsgeschichte und Öffentliches Recht an der Universität Heidelberg bekleiden. Für die

FDP/DVP zog er 1950 in den Württemberg-Badischen Landtag ein und trat in Stuttgart als entschiedener Verfechter und Gründervater des Südweststaates auf, um dessen Landesrecht und Verfassung er sich hohe Verdienste erwarb ${ }^{142}$. Als Vorsitzender des Kommunalpolitischen Ausschusses der FDP/DVP stellte er den sogenannten „GönnenweinPlan“ im Stuttgarter Landtag vor, ein Projekt, das die Grundgedanken einer regionalen Neugliederung des neuen Bundeslandes Baden-Württemberg lieferte ${ }^{143}$.

\section{Die KP in Baden und Württemberg-Hobenzollern}

Der heftigste und entschiedenste Widerspruch gegen jede Forderung nach stammesmäBiger Neugliederung und Autonomie für Südwestdeutschland kam aus den Reihen der Kommunistischen Partei. Gerhard Wohlrath, der Stellvertretende Vorsitzende der südbadischen Kommunisten, hatte sich im Sommer 1945 als unerschrockener Anhänger eines Zusammenschlusses mit den Sozialdemokraten präsentiert ${ }^{144}$ und gab für die KP ge-

${ }^{140}$ Ebenda, S. 5.

${ }^{141}$ Ebenda, S. 6.

${ }^{142}$ Laufs, Gönnenwein, S. 120.

143 Rothmund, F. D. P., S. 218.

144 Wolfrum, Besatzungspolitik, S. 55. 
genüber der französischen Besatzungsmacht folgende Einschätzung ab: Hinter dem Heimatbund und den Forderungen nach einem autonomen Alemannien stehe die schweizerische Großindustrie, die diese Bewegung finanziere ${ }^{145}$. Ausgehend von der marxistisch-leninistischen Ideologie, konnte Wohlrath nicht umhin, die schärfste $\mathrm{Ab}$ lehnung der KP gegen die Autonomiepläne zu konstatieren.

In dieser Auffassung stimmte ihm auch der Vorsitzende der KP und ehemalige evangelische Pfarrer Erwin Eckert ${ }^{146} \mathrm{zu}$, der als befähigter Politiker und brillanter Redner in der Beratenden Landesversammlung in Freiburg Stellung gegen die Ideen Fegers bezog. Nach den Ausführungen des Freiburger Oberbürgermeisters Wolfgang Hoffmann (BCSV), der aus Fegers Schwäbisch-Alemannischer Demokratie in der Beratenden Landesversammlung seitenweise zitierte, sah sich Eckert an jenem 11. April 1947 genötigt, seine Einschätzung der Autonomiepläne darzulegen. Der Vorsitzende der KP Badens warf der BCSV und insbesondere Feger vor, eine Geschichtsklitterung sondersgleichen zu betreiben. An einer Restaurierung des badischen Staates wolle die KP nicht festhalten, vielmehr forderte Eckert, daß die Länder Baden und Württemberg „zu einem der neuen Gliedstaaten der sich bildenden einheitlichen deutschen Republik" werden sollten $^{147}$. Den möglichen Vorwurf des Zentralismus wies Eckert weit von den Vorstellungen der KP, er plädierte für „die politische und nationale Einheit Deutschlands “ 148 und gegen jede Form des Föderalismus. Den Gedanken an eine föderative Gliederung Deutschlands, die Eckert mit einer Art „vereinigter Staaten und Stäätchen“ assoziierte, rückte er in die Nähe des Partikularismus. Auch mit Otto Fegers Neugliederungsvorstellungen ging Eckert hart ins Feld: Eine Autonomiebewegung, die auf abstrusen Vergewaltigungstheorien beruhe, könne mit den politischen Überzeugungen der Kommunisten nicht die kleinste Gemeinsamkeit haben. Seine Ausführungen gipfelten in der Behauptung, daß die Durchführung des föderalistischen Prinzips für Deutschland „die Kleinstaaterei des Mittelalters" nach sich ziehen werde ${ }^{149}$. Vor seinem geistigen Auge sah er die Aufspaltung in ein fränkisches und alemannisches Baden, in ein fränkisches, bayerisches und schwäbisches Bayern und ein zweigeteiltes Württemberg. In seiner Rede verschwieg Eckert geflissentlich das umfassende Konzept der stammesföderalistischen Gliederungspläne und malte statt dessen das erschreckende Bild der Biedermeierzeit ${ }^{150}$

145 „Ce que pensent les leaders des quatre partis du Heimatbund“ vom 3. 9. 1946, AdO Bade Con. Fribourg c. 2177/2.

${ }^{146}$ Erwin Eckert (1893-1972), Studium der Theologie und Philosophie in Heidelberg, Göttingen und Basel; 1911 Eintritt in die SPD; 1914 Kriegsfreiwilliger; 1919 Vikar in Pforzheim; 1922 Pfarrer in Meersburg; 1926-31 Vorsitzender des „Bundes der religiösen Sozialisten“; 1927 Stadtpfarrer in Mannheim; 1931 Ausschluß aus der SPD und Eintritt in die KPD, Entlassung aus dem Kirchendienst, Kirchenaustritt; 1931-33 Redetätigkeit für die KPD; 1933 Schutzhaft; 1936 Verurteilung wegen „Hochverrats“, Gefängnis; 1940 Angestellter in einem Betrieb in Frankfurt/ Main; 1946-50 erster Vorsitzender der KP Badens; 1946 Staatskommissar für die Politische Säuberung; 1947-52 MdL Baden; 1952-56 MdL Baden-Württemberg. Vgl. auch Köhler, Freiburg, S. 272.

${ }^{147}$ Verhandlungen der Beratenden Landesversammlung des Landes Baden, 1946-1947, S. 10; StA FR $10 \mathrm{Zf}$.

${ }_{148}$ Ebenda, S. 11.

${ }^{149}$ Ebenda, S. 12.

${ }^{150}$ Auch Hans-Peter Schwarz überschrieb das Kapitel zur Schwäbisch-Alemannischen Demokratie in Anlehnung an die Biedermeierzeit mit dem Titel: „Spitzwegstaat unter dem Schutz Frankreichs (Otto Feger)"; Ders., Reich, S. 409-413. 
und Kleinstaaterei an die Wand. Mit vorstehender Einschätzung hat Eckert maßgeblich die Linie der KP Badens geprägt ${ }^{151}$.

Auch ein weiterer führender Kommunist in Südbaden, der in Überlingen am Bodensee lebende Dr. Karl Bittel152, bekämpfte allenthalben die Autonomiepläne im Südwesten. Zu Beginn der fünfziger Jahre - Bittel war mittlerweile Leiter des „Deutschen Instituts für Zeitgeschichte“ in Ost-Berlin - erinnerte er sich an die „separatistischen Umtriebe" nach 1945. Ausgerechnet mit dem Zitat des deutschnationalen Historikers Heinrich von Treitschke „Sie warfen sich wie ein Geschmeiß hungriger Fliegen auf die blutenden Wunden des Vaterlandes" leitete Bittel das Kapitel über den "Separatismus“ in seinem Buch Die Feinde der deutschen Nation ein ${ }^{153}$. Seinen Intimfeind im Südwesten erblickte er in Bernhard Dietrich, dessen Alpenlandpläne Bittel als „eines der kuriosesten Projekte, die je in deutschen Separatistenhirnen ausgeheckt worden sind“, kolportierte $^{154}$. In Überschätzung der Rolle der Besatzungsmacht kam Bittel zu dem Urteil, daß die „Alpenländer“ nur mit Förderung der Franzosen damals „ungehemmt“ ihre Propaganda hätten betreiben können. Auch an den Plänen des „Schwäbisch-Alemannischen Heimatbundes “ ließ Bittel kein gutes Haar, einer Aufsplitterung Deutschlands in autonome Staaten konnte er nicht zustimmen, zumal er konsequent die Wiedervereinigung Deutschlands unter sozialistischen Vorzeichen propagierte. Alle Bestrebungen, die eine Schwächung der Zentralgewalt vorschlugen, enttarnten sich in Bittels Augen als Separatismus.

Der Mannheimer Führer der KP, Paul Schreck, äußerte im November 1945 gegenüber der amerikanischen Besatzungsmacht den generellen Verdacht, daß die Franzosen die

151 Scheele, Eckert, S. 295.

152 Karl Bittel (1892-1969), Studium der Geschichte, Wirtschafts- und Staatswissenschaften in Freiburg i. Br., Heidelberg und Tübingen; Mitglied in der SPD; 1915 Promotion über die Genossenschaftsbewegung; 1918 Eintritt in die KPD, Mitarbeiter des Arbeiter- und Soldatenrats in Karlsruhe; 1921 Mitarbeiter des ZK der KPD; Genossenschaftssekretär in Weißenfels (Sachsen); 1924-27 Aufenthalt in Moskau; 1933-34 Internierung im KZ Heuberg; 1935-45 zurückgezogenes Leben nahe Überlingen am Bodensee; 1945 Vorsitzender des „Antinazi-Comités Überlingen“ und Förderer der Vereinigung von Sozialdemokraten und Kommunisten; 1945-48 Mitglied des Sekretariats und der Landesleitung der KP in Baden; 1946-48 über Rudi Goguel (KP) publizistische Tätigkeit bei der Tageszeitung Südkurier in Konstanz; 1946-48 Chefredakteur der KPTageszeitung Der Neue Tag (später: Unser Tag) in Offenburg; 1949-51 Stellvertretender Leiter des "Deutschen Instituts für Zeitgeschichte" in Ost-Berlin; 1951-53 Leiter desselben; 1952 Übersiedelung in die DDR; 1957 Professor für Geschichte der Arbeiterbewegung in Berlin (Humboldt-Universität), dann in Rostock; 1958 wissenschaftlicher Berater des Außenministeriums der DDR; Emeritierung. Vgl. auch Brandt/Rürup, Volksbewegung, S. 154 und Bosch, Hoffnungen, S. 95 f. Anmerkung 6.

Unter Bittels Obhut entstand die dezidiert nach der marxistisch-leninistischen Geschichtstheorie ausgerichtete Dissertation von Karl Greese (Ders., Kampf). Gleich Bittel übersiedelte auch der Konstanzer Kommunist, Überlebender der "Cap Arcona"-Tragödie und Intimfeind Otto Fegers, Rudi Goguel (1909-1976), in den fünfziger Jahren in die DDR und fand am „Deutschen Institut für Zeitgeschichte " in Ost-Berlin eine Anstellung. Zur Biographie vgl. Goguel, Weg, 1947 (Erlebnisse) und Bosch, Hoffnungen, S. 96 Anmerkung 14. Aufschlußreich zur kommunistischen Sicht der Ereignisse am Bodensee nach 1945: Goguel, Dokumente.

153 Vgl. das Kapitel „Das verächtliche Gewerbe deutscher Separatisten“, in: Bittel, Feinde, S. 107113.

154 Bittel, Feinde, S. 112. 
„Entfachung separatistischer Tendenzen" versuchten ${ }^{155}$. Damit traf er die grundsätzlichen Vorbehalte der KP in der Neugliederungsdiskussion: Jede Form des Autonomismus konnte nur von Frankreich gesteuert sein, eine originäre südwestdeutsche Entwicklung wollte und konnte die KP nicht erkennen. Die Stellungnahme der KP zur Neugliederungsdiskussion in Südwestdeutschland ist deshalb eindeutig auf die Formel nach Ablehnung jeder Form des „Separatismus" und Schaffung einer einheitlichen deutschen „Republik" zu bringen. Für den Südwesten schlugen die Kommunisten daher die Vereinigung von Baden, Württemberg und Hohenzollern zu einem deutschen Land der sozialistisch ausgerichteten gesamtdeutschen „Republik“ vor. Anknüpfungspunkte zu den Vorstellungen von politischer Autonomie gab es mit der KP nicht.

\section{Gründungsversuche von Parteien und politischen Sammelbewegungen}

Im gesamten südwestdeutschen Raum kamen nach der Kapitulation vom Mai 1945 eine unbestimmbare Zahl von Projekten zum Vorschein, deren Ziel die Artikulation politischer Ideen bestimmter Zirkel und Kreise in der Öffentlichkeit war. Die meisten dieser Parteigründungsversuche kamen über die Phase der Programm- und Statutenplanung nicht hinaus, nur wenige Projekte wurden der Besatzungsmacht zwecks Lizenzierung vorgelegt. Doch sie alle haben, mehr oder weniger ausführlich, zur zentralen Frage der künftigen staatlichen Organisation Deutschlands und des Südwestens Stellung bezogen. Auch die Gründungsversuche von Parteien und politischen Sammelbewegungen stellen deshalb Beiträge zur Neugliederungsdiskussion dar. Außer bei der „Schwäbisch-Alemannischen Volkspartei“ steht im folgenden allerdings die paradigmatische Funktion der referierten Pläne im Vordergrund. Eine auch nur annähernde Quantifizierung der unter der Oberfläche gärenden Bemühungen geben zu wollen, muß mangels umfassenden Quellenmaterials fruchtlos bleiben. Die allermeisten Planspiele drangen niemals ans Tageslicht, und es bleibt zu vermuten, daß noch mancher Privatnachlaß solche oder ähnlich unausgegorene Parteiprogramme oder Statutensammlungen enthält.

\section{Die „Schwäbisch-Alemannische Volkspartei"}

In der ehemals freien Reichsstadt Rottweil am Neckar versammelten sich im März 1946 um den kommissarischen Bürgermeister und Oberstaatsanwalt Dr. Franz Mederle ${ }^{156}$ ein

155 Bericht der amerikanischen Militärregierung „Politisches Leben in Nord-Württemberg-Baden“ (1. 12. 1945); abgedruckt in: Borsdorf/Niethammer, Befreiung, S. 254-272, hier S. 259.

156 Franz Mederle (1893-1955), Sohn des Rottweiler Kameralamtsvorstandes; Gymnasium in Rottweil; 1914-18 Kriegsteilnehmer; Studium der Rechtswissenschaften in Tübingen; Mitglied der nichtfarbentragenden katholischen Studentenvereinigung „Alamannia“ im Kartellverband; Promotion; 1920-21 Referendar am Landgericht Rottweil, u. a. dem Landgerichtsrat Dr. Bertele (I. Zivilkammer) zugeteilt (zu B.s „Groß-Schwabenplänen“ vgl. die Einführung); um 1925 Eröffnung einer Rechtsanwaltspraxis in Rottweil; dem Zentrum nahestehend; nach 1933 Gegner des Nationalsozialismus; 1945-46 Bürgermeister von Rottweil; 1945-46 Oberstaatsanwalt am Landgericht Rottweil; 1946 Gründungsmitglied des „Schwäbisch-Alemannischen Heimatbundes“; nach 1947 erneut Rechtsanwalt in Rottweil. Vgl. auch: Schwarzwälder Volksfreund vom 
halbes Dutzend Männer, um ihre antipreußische und autonomistische Haltung durch eine Parteigründung zum Ausdruck zu bringen. Sie beschlossen, einen „SchwäbischAlemannischen Heimatbund“ ins Leben zu rufen, und erarbeiteten die in zehn Punkte untergliederten Statuten ${ }^{157}$. Auf der Grundlage einer „demokratischen und pazifistischen Politik“ postulierten die Rottweiler Honoratioren eine „interkonfessionelle“ Partei, die eine vollständige Umwandlung der „wirtschaftlichen und politischen Verhältnisse der Territorien Südwestdeutschlands“ artikulieren sollte. Eine genauere Definition des territorialen Wirkungsbereiches der beantragten Partei enthielt der zitierte Programmpunkt nicht, ein Umstand, der die französische Besatzungsmacht im Hinblick auf Vorarlberg und das Elsaß auf den Plan rufen sollte. Die Liste der Gründungsmitglieder ${ }^{158}$, die durch Unterschrift ihren Willen zur Mitarbeit kundtaten, sowie die Statuten übergab Mederle in den folgenden Tagen dem Rottweiler Kreisdelegierten Garnier-Dupré zur Weiterleitung nach Tübingen.

Rechtsanwalt Mederle befand sich seit 7. Mai 1945 als kommissarischer Bürgermeister der Stadt Rottweil durch französische Einsetzung im Amt ${ }^{159}$; als überzeugter Anti-Nazi und durch sein Engagement für den Katholizismus ausgewiesen, war seine Ernennung in weiten Teilen der Bevölkerung unumstritten gewesen. Aus seinem Standpunkt bezüglich der politischen Zukunft seiner Heimat machte Mederle in der Öffentlichkeit keinen Hehl, in der Schwarzwälder Post wurde sein Lösungsvorschlag der „schwäbischen Frage“ abgedruckt ${ }^{160}$. Im Zusammenschluß der Länder Baden und Württemberg zu einem Groß-Schwaben genannten Gebiet lag nicht die Quintessenz der südwestdeutschen Problematik, vielmehr propagierte Mederle, „das rein fränkische badische Bauland und den nördlichsten Zipfel von Württemberg“ an Bayern oder an „ein selbständiges Land Franken“ zu geben. Im Gegenzug müßte dann dem auf stämmischer Grundlage geschaffenen neuen Staat der „stammesmäßig ganz offenbar zu Schwaben gehörige, bisher bayerische Regierungsbezirk Schwaben“ zugeschlagen werden, vorausgesetzt, daß „die Bevölkerung damit einverstanden ist“. Von der Bezeichnung Groß-Schwaben rückte Mederle entschieden ab, den schlichten Name „Schwaben“ hielt er für angemessener.

3. 8. 1955. Im StadtA RW ist keine Personalakte vorhanden. Dagegen sind die Personalakten Mederles bei der Staatsanwaltschaft und im Landgericht Rottweil einschlägig; LG RW II AR $10 / 95$.

${ }^{157}$ "Statur. Schwäbisch-alemannischer Heimatbund“ vom 17. 3. 1946; AdO W-H 1f. Ser. Div. c. 2528 p. 3 d. 5 .

${ }^{158}$ Es unterschrieben neben Mederle die Rottweiler Bürger Wilhelm Ernst (Installateur; 18891968), Eugen Schäfer (Kaufmann; 1899-1964), Herbert Hugger (Kaufmann; 1910-1952), Georg Kastler (Verwaltungsangestellter; 1893-?), Josef Wittendorfer (Rathausangestellter; 1892-1975).

${ }^{159}$ Rottweiler Heimatblätter 6 (1984), ohne Seitenzählung.

${ }^{160}$ Dr. M[ederle]: Warum Groß-Schwaben?, in: Schwarzwälder Post vom 1. 2. 1946. Der Artikel Mederles entstand als Reaktion auf den am 15.1.1946 in derselben Tageszeitung auf der ersten Seite abgedruckten Artikel des Karlsruher Landesdirektors des Innern, Gustav Zimmermann, der nach dem Vorbild von Groß-Hessen einem Zusammenschluß von Baden und Württemberg zu Groß-Schwaben das Wort geredet hatte.

Gustav Zimmermann (1888-1949), 1914-18 Kriegsteilnahme; 1918-33 Redakteur und Verlagsdirektor bei mehreren sozialdemokratischen Zeitungen; 1919-33 Stadtrat in Mannheim und stellvertretender Vorsitzender der SPD in Baden; 1933 Inhaftierung im KZ Kislau; 1946-49 Landesdirektor des Innern in Württemberg-Baden; 1946-49 MdL Württemberg-Baden (SPD); 1948-49 Mitglied des Parlamentarischen Rats. Vgl. Kube/Schnabel, Südwestdeutschland, S. 90. 
Auch vor dem Antrag auf Lizenzierung einer autonomistischen Partei war Mederle mit seinen Forderungen für die französische Besatzungsmacht kein unbeschriebenes Blatt. Hatte er doch mit der Denkschrift Das deutsche Problem ${ }^{161}$ im März 1946 seine Sicht der Dinge verdeutlicht. Dabei wies er den Begriff „Separatismus“ als untauglich, da stigmatisiert, von sich. Die als dringend notwendig empfundene Umgestaltung Deutschlands durfte nicht an die Zeit nach der Reichseinheit von 1871 anknüpfen. „Das Reich als politisch-nationales Gebilde ist eine Angelegenheit der Vergangenbeit", hob Mederle als Quintessenz seiner Ausführungen hervor. Das Wiedererstehen eines deutschen Staates selbst auf bundesstaatlicher Ebene schied für den Rottweiler Bürgermeister kategorisch aus. Insgesamt hatte die Denkschrift einen meditativen Unterton, die geschichtsrevisionistischen und geschichtsphilosophischen Positionen kamen deutlicher als die Neugliederungsvorstellungen zum Vorschein. Sein engster Vertrauter, der Rottweiler Installateurmeister Wilhelm Ernst ${ }^{162}$, gab sich ebenfalls von der notwendigen Autonomie eines schwäbisch-alemannischen Staates überzeugt. Auch er besaß ab Sommer 1946 Otto Fegers Schwäbisch-Alemannische Demokratie ${ }^{163}$, in seinen Augen das Programm schlechthin für die politische Gestaltung Südwestdeutschlands. Nach dem Zusammenbruch wurden im Hause Ernst, in dem eine frankophile Grundeinstellung vorherrschte ${ }^{164}$, ab Sommer 1945 über Monate hinweg leidenschaftliche und weitschweifige Diskussionen über die Zukunft Deutschlands geführt, an denen auch fast immer Franz Mederle beteiligt war. Man stimmte überein, daß die Nationalsozialisten den Staat zerstört hätten und die einzige Lösung aus der Situation die Schaffung eines südwestdeutschen, mehrheitlich katholischen Staates sei, eben einer schwäbisch-alemannischen Demokratie. Eine offen artikulierte Antipreußenstimmung war in dieser informellen Diskussionsrunde vorhanden.

Aus dem Gesprächskreis, dessen Teilnehmer allesamt in Rottweil ansässig waren, nahmen im Laufe des Jahres 1945 die Pläne zur Gründung einer autonomistischen Partei Gestalt an. Die treibende Kraft hinter dem Projekt war sicherlich Franz Mederle, wenngleich Wilhelm Ernst eine nicht unwichtige Rolle neben dem Juristen spielte ${ }^{165}$. Auch der spätere Staatspräsident Württemberg-Hohenzollerns, Lorenz Bock, hatte als unmittelbarer Nachbar der Familie Ernst Kenntnis von den Autonomieplänen. Unentwegt hatte Franz Mederle versucht, Bock für seine Vorstellungen zu gewinnen, schließlich waren beide in der politischen Grundhaltung ähnlich gelagert und zudem in derselben Studentenvereinigung mit dem schicksalsträchtigen Namen „Alamannia“ an der Uni-

${ }^{161}$ Franz Mederle: Das deutsche Problem (masch. 10 S.); AdO HCFA AP Dir. de l'Int. c. 228 p. 19 d. 22.

162 Wilhelm Ernst (1889-1968), aufgewachsen als zwölftes von 13 Kindern einer römisch-katholischen Familie in Altheim bei Horb; 1909-12 Soldat bei der kaiserlichen Marine; 1914-18 Heizer auf einem Torpedoboot; 1918-20 Lazarett; 1924 Flaschnermeister; 1925 Übersiedlung nach Schwenningen; 1926 selbständiger Installateur in Rottweil; politisch ohne Mitgliedschaft dem Zentrum zuzuordnen; 1945-47 Erster Beigeordneter der Stadt Rottweil; 1946-48 Mitglied des „Schwäbisch-Alemannischen Heimatbundes“.

${ }^{163}$ Interview mit Willi Ernst jun. vom 30. 6. 1994; StadtA KN Cc 775 a.

${ }^{164}$ Die älteste Schwester von Ernst war mit einem französischen Bankier in Paris verheiratet; Interview mit Willi Ernst jun. vom 30.6. 1994; StadtA KN Cc 775 a.

165 Ernst nahm auch nach der Gründung des Heimatbundes regelmäßig zusammen mit Mederle an den Treffen bei Dietrich in Singen teil. 
versität Tübingen inkorporiert gewesen ${ }^{166}$. Rechtsanwalt Bock erachtete aber die wirtschaftlichen Grundlagen eines autonomen Schwabens für ungenügend. Immerhin begleitete er Mederle zu Gesprächen bei der Rottweiler Militärregierung. Der dortige Offizier der Sûreté, Albert Merglen, ließ sich von Mederle - in Anwesenheit des neugierig lauschenden Lorenz Bock - Ende März 1946 die Autonomievorstellungen für den schwäbisch-alemannischen Raum darlegen ${ }^{167}$ und setzte sich sofort mit Tübingen in Verbindung. Vom Oberdelegierten Widmer, einem eingefleischten Gegner jeder stammesföderalistischen Neugliederung, erhielt Merglen die Anweisung, nichts zu unternehmen, auf keinen Fall Mederle irgendwelche Unterstützung zukommen zu lassen und jede Fühlungnahme abzubrechen ${ }^{168}$.

Zwischenzeitlich hatte der Kreis um Franz Mederle einen revidierten Statutenentwurf an die Militärregierung übergeben. Mit Datum vom 30. März 1946 machte Mederle sein Ziel der Parteigründung in der Namensgebung deutlich: Die Statuten galten für eine zu gründende „Schwäbisch-Alemannische Volkspartei“"169. In einem entscheidenden Punkt wichen die neuen Statuten von dem ersten Antrag ab: Hieß es am 19. März noch, das Ziel des Heimatbundes sei „eine verwaltungs- und handelsmäßige Reorganisation [Südwestdeutschlands], die zur wirtschaftlichen und - eventuell - zur politischen Anbindung an unsere Nachbarn im Westen, speziell Frankreich führen wird“, wurde in den Statuten der Volkspartei vom 30. März der Passus der Annäherung gestrichen und „die verwaltungs- und handelsmäßige Reorganisation auf der Basis eines autonomen und von Preußen unabhängigen Staates" 170 gefordert.

Zur schnelleren Durchsetzung seiner Wünsche reiste Franz Mederle am 5. April 1946 nach Baden-Baden und wurde im Kabinett des Generalverwalters Laffon vorstellig. Unter vier Augen legte Mederle, der seit 1. April von Arnulf Gutknecht als Bürgermeister von Rottweil abgelöst worden ${ }^{171}$ und als Oberstaatsanwalt auf eigenen Wunsch zurückgetreten war, dem Chef de Cabinet, Pierre Bolotte, seine politischen Ambitionen dar. Handschriftlich fertigte der französische Offizier Notizen ${ }^{172}$ an. Mederle verwies auf die durch Opitz im Rheinland gegründete Rheinische Volkspartei und den Zuspruch, den eine autonomistische Bewegung in Südwestdeutschland finden würde. Überdies machte er auf das Alpenlandprojekt Dietrichs aufmerksam, dem er allerdings das Konzept eines

166 Die nichtfarbentragende katholische Tübinger Verbindung „Alamannia“ hatte neben Mederle und Bock noch weitere prominente Mitglieder: der spätere Bundeskanzler Kurt Georg Kiesinger trat wegen der "Autorität Lorenz Bocks" in die "Alamannia“ ein, in der etwa zeitgleich auch Gebhard Müller inkorporiert war; Kiesinger, Jahre, S. 84-87.

${ }^{167}$ Die Gespräche fanden zum Teil im Büro Merglens, aber auch bei Mederle statt. Es war jeweils Lorenz Bock anwesend, wobei der spätere Staatspräsident den passiven Part übernahm. Mederle hingegen redete "sehr passioniert" und überzeugt von seinen Ansichten. Merglen hatte den Eindruck, daß beide eng befreundet schienen. Schriftliche Auskünfte von Albert Merglen an den Verfasser vom 12.6. 1993 und 2. 8. 1993.

168 Schriftliche Auskunft von Albert Merglen an den Verfasser vom 12.6. 1993.

169 „Statut. Schwäbisch-Alemannische Volkspartei" vom 30. 3. 1946; AdO HCFA AP Dir. de l'Int. c. 228 p. 19 d. 22.

170 Ebenda.

${ }_{171}$ Mederle schied auf eigenen Wunsch mit Zustimmung der Militärregierung aus seinem Amt als kommissarischer Bürgermeister von Rottweil; Sitzung des Rottweiler Beirats (Gemeinderat) vom 26. 3. 1946; StadtA RW Gemeinderatsprotokolle 1945-1947.

172 Notizzettel von Bolotte vom 5. 4. 1946 mit handschriftlichem Vermerk „Dr. Mederle“; AdO HCFA AP Dir. de l'Int. c. 3304 p. 105 d. 22. 
schwäbisch-alemannischen Staates entgegenstellte, um schließlich seine Ausführungen mit heftiger Kritik an der zentralistischen Einstellung Reinhold Maiers enden zu lassen. Bolotte entließ Mederle mit der Zusicherung, die Lizenzierung der „Schwäbisch-Alemannischen Volkspartei“, deren Ziel jener mit der Schaffung eines autonomen, vorwiegend aus Baden und Württemberg bestehenden Staates, samt wirtschaftlicher Anbindung an den Westen, umschrieben hatte, zu prüfen. In Baden-Baden entschied die Direction de l'Intérieur et des Cultes schnell über den Projektantrag: Den „separatistischen Ausführungen“ Mederles fehle die Stringenz, das Ganze schien zu befremdlich zu sein. „Es scheint deshalb unnütz, sich lange mit dem Fall des Herrn Mederle aufzuhalten." Andere französische Dienststellen im Umfeld des Zivilkabinetts von Pierre Koenig wiederum teilten diese Einschätzung nicht. Der politische Berater Koenigs, Tarbé de Saint Hardouin, behandelte Mederles Parteigründungsversuch in einem Bericht an das Außenministerium en détail und stellte die "Schwäbisch-Alemannische Volkspartei“ ins Zentrum der Ausführungen zur politischen Lage in Württemberg-Hohenzollern ${ }^{174}$, einem untrüglichen Zeichen, daß gaullistische Kreise dem Projekt differenziert gegenübertraten.

Am 12. April 1946 fand ein erneutes Gespräch zwischen Bolotte und Mederle statt. Der Kabinettschef des Generalverwalters verwarf die Einschätzung der untergeordneten Direction de l'Intérieur et des Cultes und berichtete Emil Laffon ausführlich von der Angelegenheit. Zwischenzeitlich hatte der Generalverwalter ein Schreiben Mederles vom 13. März 1946 erhalten, mit der Bitte um eine grundsätzliche Stellungnahme seitens der französischen Militärregierung ${ }^{175}$. Die Informationen seines Chef de Cabinet befriedigten Laffon nicht, weshalb er über seinen Stellvertreter Grimaud vom Tübinger Oberdelegierten Widmer genauere Informationen über die Chancen einer „Schwäbisch-Alemannischen Volkspartei" erbat ${ }^{176}$. Doch General Widmer ließ sich in Anbetracht seiner Antipathien reichlich Zeit, um dann nach einem Monat zu antworten, daß Mederle wohl auf Druck der Tübinger Oberdelegation hin - den Lizenzantrag zurückgezogen habe.

Anfang Mai hat Mederle erkennen müssen, daß die Widerstände gegen eine „Schwäbisch-Alemannische Volkspartei“ auf französischer Seite unüberwindbar waren. Einem Offizier der Tübinger Oberdelegation namens Tournier gab Mederle zu verstehen, daß er statt einer Partei nun eine „kulturelle deutsch-französische Vereinigung“ gründen wolle, die er „Schwäbisch-Alemannischer Heimatbund“ nennen werde ${ }^{177}$. Zu diesem Zeitpunkt hatte er längst mit Bernhard Dietrich gemeinsame Pläne geschmiedet ${ }^{178}$.

${ }^{173}$ Handschriftliche Notiz für den Leiter der DGAA - Intérieur et Cultes - Holveck vom 11. 4. 1946; AdO HCFA AP Dir. de l'Int. c. 228 p. 19 d. 22.

${ }_{174}$ Saint Hardouin an Bidault vom 25. 6. 1946 (masch. 30 S.). Darin: ${ }_{n}$ Liste des partis en instance d'autorisation“ (31.5. 1946): „Schwäbische Alemannische Volkspartei“; MAE Z-Europe Allemagne 1944-1960 49.

175 Mederle an Laffon vom 13. 3. 1946; AdO W-H 1 f. Ser. Div. c. 2528 p. 3 d. 5.

176 Grimaud an Widmer vom 26. 4. 1946; ebenda.

177 Widmer an Laffon vom 17. 5. 1946; AdO HCFA Dir. de l'Int. c. 228 p. 19 d. 22.

${ }^{178} \mathrm{Zum}$ nSchwäbisch-Alemannischen Heimatbund“ vgl. Kapitel III/4. In französischen Quellen sieht man von dem Notizzettel Bolottes von Anfang April $1946 \mathrm{ab}$ - wird erstmals explizit die Zusammenarbeit von Mederle mit Dietrich im Juni 1946 erwähnt; vgl. Synthèse Rapport 06/46 Wurtemberg, S. 4; AdO CCFA AC c. 660/4. 


\section{Die „Süddeutsche Volkspartei für Aufbau und inneren Frieden“}

Der Freiburger Oberdelegierte Schwartz bezeichnete im Januar 1946 in einem Bericht über die Lage im französisch besetzten Teil Badens den Wunsch des Zeppelinbauers Dr. Hugo Eckener, „eine ,Süddeutsche Volkspartei für Aufbau und inneren Frieden“ zu schaffen“, als ein bemerkenswertes Vorkommnis ${ }^{179}$. Eckener hatte dem Konstanzer Bezirksdelegierten Degliame ein Programm übergeben, das von dem Grafen Robert Douglas ${ }^{180}$, dem Leiter des Singener Aluminiumwerkes, Dr. Hans Constantin Paulssen, dem Freiburger Historiker Gerhard Ritter und dem vormaligen Konstanzer Oberbürgermeister Hans Schneider getragen wurde. Verblüfft bemerkte Schwartz, „daß das Projekt auch die Ideen des Alpenlandes wiederaufnimmt, aus der Region Konstanz hervorgegangen ist und durch Personen, die sicherlich Beziehungen zur ,Deutsch Nationalen Partei' hatten, repräsentiert wird“"181.

Das Programm der „Süddeutschen Volkspartei für Aufbau und inneren Frieden“ 182 konnte nicht Urteilsgrundlage für die Auffassung von General Schwartz gewesen sein. Von einem Zusammenschluß der süddeutschen, katholischen Staaten zu einem „Alpenland" findet sich im Programm keine Andeutung; als Hauptaufgaben der Volkspartei hatte Hugo Eckener hingegen die innere Befriedung, den wirtschaftlichen Wiederaufbau und die Integration der ostdeutschen Flüchtlinge und Vertriebenen definiert ${ }^{183}$. Die projektierten Ziele sollten auf der Grundlage der folgenden Programmpunkte verwirklicht werden: Die Garantie der geistigen Freiheit des einzelnen, der Ausbau des sozialen Netzes, eine „Kulturpolitik auf christlicher Grundlage“ sowie die Garantie der Religionsfreiheit, die Entnazifizierung, eine wirtschaftliche Zusammenarbeit "mit den Nachbarvölkern“ und die „Ablehnung des Listenwahlsystems“. A uf Distanz begab sich Eckener von allen „bewußt partikularistischen und separatistischen Tendenzen", und er führte über die politische Struktur Nachkriegsdeutschlands aus: „Anstrebung eines föderalistischen Aufbaues im deutschen Staats- und Wirtschaftsbereich."184 In dem Programmentwurf konnte der Freiburger Oberdelegierte keinesfalls eine Nähe zu den Alpenlandplänen Dietrichs gefunden haben. Auch die hinter der „Süddeutschen Volkspartei für Aufbau und inneren Frieden " stehenden deutschnationalen Männer - mit einer Ausnahme boten nur schwerlich Anknüpfungspunkte zu den Plänen einer alpinen Union.

179 Bade - Rapport mensuel [Januar 1946]; AdO CCFA Cab. Civil c. 40 Pol III H d. 2.

${ }^{180} \mathrm{Zu}$ Graf Robert Douglas vgl. Kapitel II/2.

181 Bade - Rapport mensuel [Januar 1946]; AdO CCFA Cab. Civil c. 40 PoL III H d. 2. Es ist wahrscheinlich, daß sich der französische Journalist Louis Parrot bei der Abfassung seines Artikels über die Alpenlandbewegung auf interne Informationen der Militärregierung stützen konnte. Auch er verdächtigte Paulssen, Graf Douglas und Eckener der Propaganda für eine alpine Union; Louis Parrot: „,Avec Dieu, vers le nouvel Occident!' proclame Jules Wachter", in: Ce Soir vom 19. 2. 1946.

182 Ein Entwurf des Parteiprogrammes ist im Nachlaß des Freiburger Historikers Gerhard Ritter überliefert, in den französischen Quellen fand sich davon keine weitere Spur; BAK NL [Gerhard Ritter] 166/287. Die Protagonisten verwendeten anfangs die Bezeichnung "Volksbund“, in den französischen Unterlagen ist durchgängig von einer "Volkspartei“ die Rede.

183 „Süddeutscher Volksbund für Aufbau und inneren Frieden“ [Dezember 1945], S. 2; BAK NL [Gerhard Ritter] 166/287.

184 Ebenda. 
Der gebürtige Flensburger Dr. Hugo Eckener ${ }^{185}$, der rund fünfzig Jahre in Friedrichshafen gelebt und seine Schaffenskraft den Zeppelinen verschrieben hatte, war 1944 auf der Flucht vor schweren Bombenangriffen nach Konstanz ins Haus seiner Tochter gezogen. In der Bodenseemetropole schmiedete er 1945 Pläne zur Gründung der „Süddeutschen Volkspartei für Aufbau und inneren Frieden“. Allen Unkenrufen zum Trotz ${ }^{186}$ hatte er im Herbst 1945 Kontakte zu namhaften Persönlichkeiten aufgenommen und die geplante Parteigründung vorangetrieben. Sein national-konservatives politisches Denken hatte er sich aus der Weimarer Republik in die unmittelbare Nachkriegszeit hinübergerettet; im Herbst 1945 dachte die französische Besatzungsmacht über seine Einsetzung als Konstanzer Oberbürgermeister nach ${ }^{187}$. Doch Eckeners Wunsch, das abgesetzte Stadtoberhaupt Hans Schneider als rechte Hand zu erhalten, machte den Plan obsolet.

Die belastete Vergangenheit Hans Schneiders, der das Programm der „Süddeutschen Volkspartei für Aufbau und inneren Frieden“ mitunterzeichnet hatte, rief tiefes Mißtrauen bei der französischen Besatzungsmacht hervor. Seine Tätigkeit nach 1938, zuerst als Regierungsrat in der Vorarlberger Regierung und dann bei Gauleiter Hofer in Innsbruck, wurde für Hans Schneider zum Verhängnis ${ }^{188}$; seine nationalsozialistische Überzeugung hatte ihn diskreditiert. Von der konzept- und planlos agierenden französischen Militärverwaltung wurde er dennoch im Juni 1945 zum Oberbürgermeister von Konstanz berufen ${ }^{189}$, er selbst hat allerdings bereits im Oktober desselben Jahres um die Annahme seines Rücktrittsgesuchs gebeten. Obwohl er vor 1933 als Vertreter des Zentrums gegolten hatte, dürfte sein Name unter dem Programm der „Süddeutschen Volkspartei für Aufbau und inneren Frieden“ die Chancen der Zulassung kaum gesteigert haben.

Auch Gerhard Ritter ${ }^{190}$, der in späteren Jahren dem protestantischen Flügel der CDU zugerechnet wurde, hat in Kenntnis der politischen Pläne des Singener Bürgermeisters jede Form des Autonomismus scharf abgelehnt. „Im französisch besetzten Baden und Württemberg hat sich eine, alpenländische ${ }^{c}$ Bewegung aufgetan, die einen süddeutsch $k a-$

${ }^{185}$ Hugo Eckener (1868-1954), 1888 Abitur in Flensburg (Gymnasium am Klostergang); 18881892 Studium an den Philosophischen Fakultäten in München, Berlin und Leipzig; 1892 Promotion; 1899 Umzug nach Friedrichshafen; 1908 Kontakte zu Graf Zeppelin; 1911 „Luftschifführer für Zeppeline“; 1914-16 Ausbilder von „Marineluftschiffkommandanten“; 1916-18 Einsatz als Zeppelinkommandant; Direktor der "Deutschen Luftschiffahrts-Aktien-Gesellschaft" in Friedrichshafen; 1944 Umzug nach Konstanz; 1945 Mitherausgeber des Südkuriers; 1947 Geldstrafe im Rahmen der Entnazifizierung. Vgl. Italiaander, Deutscher. Die Memoiren (Eckener, Zeppelin) enthalten keine Hinweise zum politischen Handeln nach 1945.

186 Kritiker sahen die Parteigründung als fatal für Eckener an, da sich die „Volkspartei“ nur auf das Vertrauen der Bevölkerung in den bekannten und beliebten Zeppelinbauer stützen könne. Vgl. den Brief eines Ravensburger Juristen an Eckener; zitiert in: Italiaander, Deutscher, S. 424.

${ }^{187}$ Eckener an den Konstanzer Bezirksdelegierten d'Alauzier vom 30.10. 1945; vgl. Italiaander, Deutscher, S. 416.

${ }^{188}$ Vgl. dazu die Korrespondenzen des späteren Konstanzer Landrates Rudolf Belzer mit Leo Wohleb; StA FR T1 NL Leo Wohleb I/1 43.

${ }^{189}$ Schneider wurde von General Lavilleon (14.D.I.) und nicht von der zuständigen Konstanzer Bezirksmilitärregierung am 15.6. 1945 ins Amt berufen; StadtA KN S II 13605. Ausführlich: Klöckler, Besatzungspolitik, S. $39 \mathrm{ff}$.

190 Gerhard Ritter (1888-1967), 1912 Dissertation bei Hermann Oncken in Heidelberg; 1915-19 Leutnant d. R.; 1921 Habilitation in Heidelberg; 1925-56 Professor für deutsche Geschichte in Freiburg i. Br.; 1938-44 im Widerstand; 1944-45 Gestapohaft und Inhaftierung im KZ Ravensbrück; 1949-53 Vorsitzender des Verbands deutscher Historiker; Gegner Fritz Fischers in der Kontroverse um die deutschen Kriegsziele im Ersten Weltkrieg. Vgl. Schwabe, Ritter. 
tholischen Staat etwa im Gebiet des alten Vorderösterreich, aber unter dem Protektorat Frankreichs, eines neukatholisch gewordenen Frankreich, errichten möchte“, notierte Ritter in einem politischen Lagebericht im Dezember 1945191. Zugleich befürchtete er, daß die französische Besatzungsmacht planmäßig die gesamten Leitungsebenen mit Südwestdeutschen besetzen könnte, wodurch er seine eigene Position an der Freiburger Universität gefährdet sah; „nichtalemannische und nichtschwäbische Professoren scheiden dann nach und nach von selber aus "192, vermutete Ritter. Dementsprechend war er auf den Vorschlag Otto Fegers, einen schwäbisch-alemannischen Staat zu gründen, nicht gut zu sprechen, vielmehr erblickte er in Fegers Buch eher das „Symptom der geistigen Gärung “ als einen ernstzunehmenden politischen Faktor ${ }^{193}$. Schon vor dem offiziellen Erscheinen kannte Gerhard Ritter den Inhalt der Scbwäbisch-Alemannischen Demokratie; Friedrich Metz, der Leiter des Alemannischen Instituts, hatte ihm nämlich bereits im Mai 1946 die Druckfahnen übersandt, die jener in einer Sitzung des Alemannischen Instituts direkt von Feger erhalten hatte. Die Entrüstung auf seiten des Freiburger Historikers war groß, Ritter titulierte das Buch als „Machwerk" und verurteilte scharf „den schamlosen Separatismus des politischen Teiles" 194 . Seinem Freund Metz, der von ihm ein Leumundszeugnis für die Entnazifizierung erhalten sollte ${ }^{195}$, brachte er seine ganze Abscheu über den Fegerschen Standpunkt in einem prägnanten Satz zum Ausdruck: „Es hat doch etwas unheimliches zu sehen, was sich heute alles an Gesinnungslosigkeit und Borniertheit ans Licht wagt." 196

Der nationale Standpunkt der vorgenannten Männer ließ selbstredend keine Verbindung mit dem Projekt einer autonomen, schwäbisch-alemannischen Demokratie oder eines konföderierten Alpenlandes erkennen. Bleibt die Frage zu klären, weshalb General Schwartz die „Süddeutsche Volkspartei für Aufbau und inneren Frieden“ mit den Zielen der Alpenlandbewegung in Verbindung brachte. Der Leiter des Aluminiumwerkes in Singen am Hohentwiel, Dr. Hans Constantin Paulssen ${ }^{197}$, ist der Schlüssel zur Lösung.

${ }^{191}$ Gerhard Ritter: Über unsere politische Lage (masch. 35 S.) [Dezember 1945], S. 22; BAK NL [Gerhard Ritter] 166/288.

192 Ebenda.

${ }^{193}$ Gerhard Ritter: Über unsere politische Lage. 4. Bericht (masch. 34 S.) [April 1947], S. 34; BAK NL [Gerhard Ritter] 166/288.

194 Ritter an Metz vom 13.6. 1946; BAK NL [Gerhard Ritter] 166/327.

${ }^{195}$ Gerhard Ritter stellte Metz am 8. 5. 1947 ein umfangreiches Leumundszeugnis aus, das Metz dringend benötigte; BAK NL [Gerhard Ritter] 166/329.

${ }_{196}$ Ritter an Metz vom 13. 6. 1946; BAK NL [Gerhard Ritter] 166/327.

197 Hans Constantin Paulssen (1892-1984), Gymnasium in Weimar; Studium der Rechtswissenschaften in Frankreich, München, Jena und Freiburg i. Br.; 1914 Promotion; 1914-18 Kriegsfreiwilliger (Leutnant einer Gebirgs-Maschinengewehrabteilung); 1919 Übernahme in die Reichswehr; 1920 Teilnahme am Kapp-Putsch; 1920 Leitender Angestellter der Singener Firma Dr. Lauber, Neher \& Co.; 1924 Direktor der Aluminium-Walzwerke in Singen a. Htwl.; 1939 Einberufung zur Wehrmacht, Uk-Stellung; Generaldirektor der ALIG (Aluminium-IndustrieGesellschaft, einem Zusammenschluß aller schweizerischen Aluminiumbetriebe in Deutschland); 1940 Wehrwirtschaftsführer; 1945 Suspendierung von allen Ämtern und Beschlagnahmung des kompletten Vermögens; 1948 Einstufung als "Mitläufer ohne Sühnemaßnahmen“; 1948 erneute Leitung der Aluminium-Walzwerke in Singen; 1949 Präsident der Industrie- und Handelskammer Konstanz; 1950-57 1. Präsident der Deutsch-Französischen Vereinigung in Konstanz; 1953-64 Präsident der Bundesvereinigung der Deutschen Arbeitgeberverbände; 1955 Ehrenbürger der Stadt Singen; Gründungsmitglied der Gesellschaft der Freunde und Förderer 
Selbstredend war Paulssen nach 1945 nicht von seinem deutschnationalen Standpunkt abgerückt, aber er hatte ökonomisch motivierte Pläne durchdacht, in deren Zentrum die Schaffung eines wirtschaftlich autonomen Südstaates stand, was in bestimmten Kreisen der Militärregierung als Vorstadium einer alpinen Union gesehen wurde. Bei Paulssen, dem Großindustriellen par excellence, spielte die stämmische Gliederung nur eine untergeordnete Rolle, wenngleich er die schwäbisch-alemannische Stammeszugehörigkeit als Vorteil bei dem Zusammenschluß von (Süd-)Baden, (Süd-)Württemberg und Hohenzollern einordnete. Den Südstaat glaubte er mit Unterstützung des Freiburger Erzbischofs Conrad Gröber, dem er in der Neugliederungsfrage eine politische Rolle zusprechen wollte, weiter lancieren zu können. Seine Südstaatausarbeitungen erreichten den Kirchenmann Mitte Januar 1946198. Die Argumentation bezog Paulssen über weite Strecken aus dem Bereich der Wirtschaft: Der Mangel an Rohstoffen, von denen die verarbeitende Industrie im Südteil der FBZ abhängig sei, werde nach dem Abbau der Lagerbestände zu „bedenklichen Notständen“ führen. Der Handel mit Frankreich via Elsaß würde zweifellos eine Besserung bringen; zudem fühlte sich Paulssen durch die Freiburger Rede de Gaulles vom Oktober 1945 bestärkt. Der Wirtschaftsverkehr mit Frankreich könne aber nur von einer zentralen deutschen Verwaltung im Südteil der FBZ durchgeführt werden. Die Schaffung eines Zonen- oder Südstaates hatte bei Paulssen oberste Priorität. „Aber weder in der soziologischen noch in der wirtschaftlichen Struktur der drei Landesteile ${ }^{199}$ sind Gegensätze oder beträchtliche Unterschiede vorhanden, sondern vielmehr grösste Ähnlichkeit." 200 Ausgehend von wirtschaftlichen Erwägungen kam Paulssen zu dem Schluß, daß der Südstaat problemlos zu errichten sei: „Die Schaffung eines einheitlich verwalteten Zonenlandes mit einer politisch verantwortlichen Regierung dürfte heute so sehr den Interessen der gesamten Bevölkerung entsprechen, dass mit einem Widerspruch nicht zu rechnen ist. “201 Nötigenfalls trat der „Separatist“ Paulssen sogar für die Herausgabe einer eigenen Währung ein. Der Industrielle verstand seinen Vorschlag - trotz Ausgabe einer eigenen Währung - nicht als Aufforderung zur Schaffung eines autonomen Südwestens; „kommt die Reichseinheit“, erläuterte er, „so steht nichts im Wege, dieses Zonenland [...] in das Ganze einzugliedern." Zur Umsetzung dieses Plans wollte er den Erzbischof für die Bildung eines Komitees zur Gründung einer politischen Partei gewinnen, „dessen Programm in der Schaffung dieses Zonenlandes ${ }^{202}$, seiner Verfassung und

der Universität Konstanz; 1968 Chevalier de la Légion d'Honneur. Ausführliche Biographie bei: Kappes, Bürgermeister, S. 197-201.

${ }^{198}$ Hans Constantin Paulssen: [„Der Südstaat"] (masch. 5 S.) vom 9. 1. 1946; EAF NL Gröber $\mathrm{Nb} 8 / 63$. Derselbe Text befindet sich unsigniert und mit engerem Zeilenabstand abgeschrieben unter dem Titel "Landesbildung in der französischen Südzone“ (masch. 4 S.) im StadtA KN „Depositum“ Feger.

199 Hohenzollern blieb bei dieser Zählung außen vor, Paulssen nannte explizit die südlichen Teile von Baden und Württemberg sowie den bayerischen Landkreis Lindau als Bestandteile des Südstaates.

200 Hans Constantin Paulssen: [„Der Südstaat“] (masch. 5 S.) vom 9. 1. 1946, hier S. 5; EAF NL Gröber Nb 8/63.

${ }^{201}$ Ebenda.

${ }^{202}$ Den Terminus „Südstaat" benutzte Paulssen in seiner Denkschrift nicht, die Bezeichnung als „Zonenland" lag ihm näher. Mit dem Plan einer eigenen Währung, einer eigenen Verfassung und Regierung liefen Paulssens Pläne aber auf die Gründung eines selbständigen Staates hinaus, im konkreten Falle eben des Südstaates, wie er auch von französischer Seite erwogen wurde. Vgl. dazu Kapitel I/4. 
seiner Regierung läge" ${ }^{203}$. In Erzbischof Dr. Conrad Gröber ${ }^{204}$ erblickte Paulssen den Initiator einer Neugliederung im Südwesten, eine Rolle, in der sich der national und staatskirchenrechtlich denkende Oberhirte nicht gefallen konnte. Umfaßte die Diözese Freiburg doch das gesamte Baden und Hohenzollern; hingegen unterstand Südwürttemberg der Diözese Rottenburg unter Bischof Johannes Baptista Sproll. Hätte nicht der oberrheinische Metropolit mit der politischen Neugliederung auch die Veränderung kirchlicher Strukturen einleiten müssen? Aber mit solchen Gedanken war Erzbischof Gröber nach 1946 sicherlich nicht beschäftigt, galt er doch als ausgewiesener Gegner der von Otto Feger propagierten autonomen schwäbisch-alemannischen Staatsbildung ${ }^{205}$. Der Generalvikar der Erzdiözese und letzte Führer des Badischen Zentrums, Prälat Dr. Ernst Föhr ${ }^{206}$, hatte sich in seinen Äußerungen weiter vorgewagt: Im Falle einer langen Besatzung und mit Freiburg als Hauptstadt befürwortete Föhr gegenüber Vertretern der Besatzungsmacht die Bildung des Südstaates ${ }^{207}$.

Die Südstaatausarbeitungen Paulssens waren dem Freiburger Oberdelegierten Schwartz bekannt, die Vielzahl der Projekte hat allerdings seinen Blick für die Kernforderungen der einzelnen Gruppen getrübt. Auch der kommunistische Konstanzer Bezirksdelegierte Degliame, ein Feind jeder möglichen stammesmäßigen Neugliederung, dürfte seinem Freiburger Vorgesetzten nur tendenziös Bericht erstattet haben. Als Schwartz die Pläne Paulssens und die spärlichen Berichte Degliames, der sich zumal erst seit zwei Monaten in Konstanz aufhielt, zusammenfügte, kam er im Januar 1946 zu der falschen Einschätzung, daß die „Süddeutsche Volkspartei für Aufbau und inneren Frieden" den Versuch der Alpenlandbewegung darstelle, politisch tätig zu werden. Die Lizenzierung der Partei erübrigte sich allerdings recht schnell, noch in der Planungsphase nahm Eckener Abstand von seinem Vorhaben. Die von Marcel Degliame veranlaßte personelle Umgestaltung der in Konstanz erscheinenden Tageszeitung Südkurier ${ }^{208}$ hatte Eckener das für nötig erachtete Sprachrohr genommen ${ }^{209}$ und seinen Plänen den Todesstoß versetzt.

${ }^{203}$ Hans Constantin Paulssen: [„Der Südstaat“] (masch. 5 S.) vom 9. 1. 1946, hier S. 5; EAF NL Gröber $\mathrm{Nb} 8 / 63$.

${ }^{204}$ Conrad Gröber (1872-1948), 1891 Abitur in Konstanz; 1891-93 Studium der katholischen Theologie in Freiburg i. Br., 1893-98 Fortsetzung des Studiums in Rom (Gregoriana); 1897 Priester in Rom; 1898 Promotion; 1898 Vikar in Ettenheim; 1898 Kaplan in Karlsruhe; 1901 Rektor des erzbischöflichen Konvikts „Konradihaus“ in Konstanz; 1905 Pfarrer in Konstanz; Stadtverordneter in Konstanz (Zentrum); 1922 Münsterpfarrer in Konstanz; 1925 Domkapitular in Freiburg; 1931 Bischof von Meißen; 1932 Erzbischof von Freiburg; 1947 päpstlicher Thronassistent. Vgl. weiter Keller, Gröber und Ott, Gröber.

${ }^{205}$ Hug, Erzbischof, S. 241.

206 Zur Biographie Föhrs vgl. Kapitel II/1.

${ }^{207}$ Französische Sondierung zum Zusammenschluß der Südzone (o. D.); AdO Bade AP Sec. Pol. c. 2801.

${ }^{208}$ Eckener zählte neben Johannes Weyl, Paul Christiani und Carl Diez zu den Teilhabern der Kommanditgesellschaft, die von Degliame am 7.2. 1946 aufgelöst worden war. Der Südkurier wurde sodann einer aus drei Parteien (Sozialisten, Kommunisten und Christlich-Sozialen) gebildeten Gesellschaft überstellt; Klöckler, Besatzungspolitik, S. $79 \mathrm{f}$.

209 „Ja, ich habe meinen Plan, eine neue Partei zu gründen in der Tat aufgegeben, aufgeben müssen, weil uns der ,Südkurier' genommen ist, den ich in erster Linie für die Propaganda hätte anspannen müssen“, Eckener an Ritter vom 21.2. 1945; BAK NL [Gerhard Ritter] 166/327. 


\section{Die „Christlich-Soziale Sammlung“}

Erzbischof Conrad Gröber hatte erstmals im August 1945 einen Vorschlag zur Schaffung einer politischen Sammelbewegung erhalten. Paul Frank aus Singen am Hohentwiel suchte das Interesse des Oberhirten der Diözese Freiburg durch eine Sammelbewegung auf christlichem Fundament zu wecken ${ }^{210}$. "Christlich-Soziale Sammlung" sollte die zunächst auf „Oberbaden“ begrenzte Partei heißen; eine Wiedergründung der vor 1932 ins Leben gerufenen Parteien lehnte Frank kategorisch ab. Die Idee des „Abendlandes“ war in dem Singener Bürger wachgeblieben, er bezeichnete sich als einen, „der für das Abendland spricht“. In einem Rundumschlag rechnete er mit den Parteien der Weimarer Republik ab und kam zu dem Ergebnis, daß die Bevölkerung die alten Parteien ablehne. In der "Christlich-Sozialen Sammlung" sah Frank den Schmelztiegel der heimat- und europatreuen Kräfte. „Wir sind gewillt, aus den Verirrungen der letzten 150 Jahre preußisch-deutscher Geschichte zu lernen und Konsequenzen zu ziehen“, ein klares Bekenntnis also zur abendländischen Geschichtsrevision.

Die „Christlich-Soziale Sammlung" bekenne sich, so Frank, zum Christentum, zur Humanität, zum Pazifismus, zur sozialen Tat, zum föderalistischen Gedanken und zur Ständeordnung. Antiborussianismus und heißblütiger Wunsch nach weitgehender Dezentralisation bestimmten die Ausführungen bezüglich des Staatsaufbaus. „Nicht Kolonialvolk im eigenen Reich" sollte der schwäbisch-alemannische Stamm sein, sondern die Heimat galt Frank „als Ausgangspunkt aller politischen und kulturellen Impulse“. Die Struktur des zukünftigen Deutschlands umschrieb Frank mit folgenden Worten: „Die Christlich-Soziale Sammlung fordert die Föderation der deutschen Stämme unter Beibehaltung der wirtschaftlichen Einheit. "Umgesetzt in konkrete Forderungen hieß dies für Südwestdeutschland: Bildung eines schwäbisch-alemannischen Staates unter Einschluß von Bayerisch-Schwaben. Der schwäbische Stammesstaat sollte dann mit den Bayern, den Franken und den restlichen deutschen Stämmen eine Föderation unter „Beibehaltung der wirtschaftlichen Einheit" bilden. Franks Konzept ist an diesem Punkt zweideutig; sowohl ein Bundesstaat mit auf stämmischer Grundlage gebildeten Ländern als auch ein Staatenbund mit weitgehender Autonomie der Teilnehmer war denkbar. Erzbischof Gröber hat auf dieses, wie auch auf andere politische Konzeptionen nie geantwortet, für ihn stand die Schaffung einer überkonfessionellen christlichen Partei im Vordergrund, die deutsche Einheit stellte er zu keinem Zeitpunkt in Frage.

\section{Der „Christlich-Soziale Volksbund Südbadens“}

Anonym erhielt Gröber wahrscheinlich 1945 das Programm des „Christlich-Sozialen Volksbundes Südbadens“, das inhaltlich nicht mit den Vorstellungen Franks und der "Christlich-Sozialen Sammlung" übereinstimmt und somit einem anderen Umfeld entsprungen sein muß211. Es deutet manches auf die Urheberschaft des Singener Journalisten und Föderalisten Rudolf Woller ${ }^{212}$, später Chefredakteur des ZDF, hin. Augenfäl-

210 Paul Frank: Christlich-Soziale Union (masch. 6 S.) [August 1945]; EAF NL Gröber Nb 8/60. Dort auch die folgenden Zitate.

211 o. A.: [Christlich-Sozialer Volksbund Südbadens] [1945/46] (masch. 4 S.); EAF NL Gröber Nb $8 / 60$.

212 Rudolf Woller (1922-1996), Jagdflieger bei der Luftwaffe; 1946 Volontär bei der Tageszeitung 
ligste Programmpunkte waren die Ablehnung der konfessionellen Grenzen bei der Parteiarbeit, die Mitwirkung der Kirchen im öffentlichen Leben, die Forderung nach einem Zweikammersystem (Politische Repräsentanz/Berufsstände und Körperschaften) und die Verwerfung des „Kollektivismus“. Die staatliche Neugliederung Deutschlands wurde nach folgenden Prinzipien erwogen: „Wir lehnen für die künftige Stellung Deutschlands eine Vormachtstellung Preussens ab, wir erstreben vielmehr die Gliederung Deutschlands in natürlich und geschichtlich gewachsene Länder und deren Zusammenschluss zu einem deutschen Bundesstaat, der nötigenfalls durch die Bildung grösserer deutscher Ländergruppen vorbereitet werden kann. "213 Baden und Württemberg waren in den Augen des Verfassers sicherlich geschichtlich gewachsene Länder, seine Stellung zu einem Südstaat oder Südweststaat ist deshalb ambivalent. Mit der Bildung „grösserer deutscher Ländergruppen“ kann sowohl ein föderativer Zusammenschluß in Form eines Bundesstaates oder aber eine Konföderation der süddeutschen Länder Baden, Württemberg und Bayern gemeint sein. Weiterhin ist auch eine Neugliederung des Südwestens mit dieser Definition abgedeckt. Strikt abgelehnt wurde „jede Form des Separatismus“; der engen wirtschaftlichen Zusammenarbeit „auf der Grundlage der Gleichberechtigung und der gegenseitigen Achtung" mit den Nachbarn Frankreich und der Schweiz wurde jedoch im gleichen Atemzug das Wort geredet ${ }^{214}$.

\section{Die „Demokratisch Soziale Volksgemeinschaft"}

Mitte Juni 1946 richtete Ernst Broszeit, ein Wirtschaftsprüfer aus Sölden bei Freiburg, eine Denkschrift an den französischen Außenminister Georges Bidault ${ }^{215}$. Die „Demokratisch Soziale Volksgemeinschaft" (DSV) war von Broszeit und seinem Zirkel als eine gesamtdeutsche Partei konzipiert, die einer zentralen Lenkung bedurfte. Schon bei der Lektüre dieses Abschnittes dürften die französischen Offiziere in Baden-Baden das Programm ad acta gelegt haben. Eine zentrale Leitung der Partei erachtete Broszeit als unbedingt notwendig, um mögliche Richtungskämpfe in den Besatzungszonen zu vermeiden. Das Ziel der DSV sei die Schaffung einer deutschen Föderation in Form eines Staa-

Südkurier; Journalist bei verschiedenen Tageszeitungen und Redakteur beim SWF; 1962-70 Leitung des Bonner Studios des ZDF; 1969-78 Präsident des Verbandes der Reservisten der Bundeswehr (Oberst d. R.); 1971-76 Chefredakteur des ZDF; 1977-96 Pferdezucht auf seiner Farm in Kanada; 1982 Großes Bundesverdienstkreuz.

Woller trat nach 1945 gegenüber der französischen Besatzungsmacht als Föderalist hervor. Noch Ende 1948 schlug er angesichts der baldigen Konstituierung der Bundesrepublik Deutschland ["un état unifié fortement centralisé"] die Schaffung einer Zeitung vor, die entschieden auch gegen den Zentralismus im Südwesten Partei beziehen sollte. Der Südweststaat [nunifié et centralisé avec Stuttgart comme capitale“] wäre Hauptangriffsziel des Organs gewesen; mit Walter Ferber [vgl. Klöckler, Ferber], dessen Föderalismusvorstellungen auf der Reorganisation von Baden fußten, wußte sich Woller explizit verbunden; „Projets des milieux fédéralistes de SingenConstance" vom 10. 12. 1948; AdO Bade AP c. 2157/3.

${ }^{213}$ Ebenda, [S. 1].

214 Ebenda.

215 Broszeit an Bidault vom 13.6. 1946; AdO HCFA Cab. Civil POL-II-B p. 27. Dem Anschreiben sind die Statuten (masch. 15 S.) und das „Aktionsprogramm" (masch. 7 S.) der DSV beigefügt. In den Unterlagen der Oberdelegation Baden ist ein Dossier zur geplanten Partei von Broszeit vorhanden ("Union populaire démocratique et sociale“), das weiteres Material (u. a. die Namen der fünf Gründungsmitglieder) beinhaltet; AdO Bade Sec. Pol. c. 2157/3 p. 56. 
tenbundes, der aus dreizehn Föderativstaaten bestehen sollte. Die ostdeutschen Landschaften zählte der Freiburger Wirtschaftsprüfer als Föderativstaaten hinzu (Ostpommern, Ostpreußen, Schlesien), im Norden sollte Niederdeutschland (Hannover, Schleswig-Holstein, Braunschweig und Teile Westfalens), Mecklenburg-Vorpommern und Brandenburg entstehen. West- und Mitteldeutschland bekämen folgendes staatliches Gesicht: Sachsen, Thüringen, Hessen (Hessen-Nassau und Teile von Hannover), Rheinland und Franken (Saargebiet, Rheinpfalz, Hessen südlich des Mains und von Bayern Main-Franken, Mittel-Franken und Ober-Franken). Der bayerische Staat sollte auf die Oberpfalz, Nieder- und Oberbayern schrumpfen. Dem deutschen Südwesten ließ Broszeit durch die staatliche Zusammenfassung von Baden, Württemberg und Bayerisch-Schwaben einen großen Föderativstaat angedeihen, dem er den Namen „Schwaben“" verlieh. Die französische Besatzungsmacht reagierte auf die Parteipläne, indem sie jede weitere Betätigung verbot. Bleibt aber auch bei Broszeit und seinem Zirkel festzuhalten, daß ein schwäbisch-alemannischer Föderativstaat, d. h. ein weitgehend autonomer Staat innerhalb eines deutschen Staatenbundes, gewünscht wurde.

\section{Das „Freie Südwestdeutschland“}

Von einer antipreußischen Haltung sondergleichen zeugt der Versuch, von der amerikanischen Militärregierung eine Lizenz für eine Partei „Freies Südwestdeutschland“ zu erhalten. Verfasser und Protagonist des „Freien Südwestdeutschlands“ war Friedrich Kächele aus Mühlbach bei Eppingen in Nordbaden. Die umfangreiche, undatierte Denkschrift Die Bildung eines freien Staates Südwestdeutschland ${ }^{216}$ erweist sich allerdings über weite Strecken als Autobiographie des Verfassers, der sich darüber hinaus auf „1173 Mitglieder" berief. Weder Umfeld noch Größenordnung der Pläne sind freilich realistisch. Dennoch spiegelt sich auch in diesem Vorschlag die Stimmung der ersten Nachkriegsjahre wider. Kächele vertrat Pläne, deren territoriale Ausdehnung 1948 von Friedrich Metz, dem Leiter des Alemannischen Instituts in Freiburg, in Buchform (Rheinschwaben) publik gemacht wurde. Das freie und neutrale Südwestdeutschland sollte aus Baden, Württemberg, der Pfalz und dem Saargebiet - falls nicht von Frankreich annektiert - zusammengesetzt werden. Ein stammesmäßiger Aspekt fehlte bei Kächele vollkommen, vielmehr standen der Neutralitätswunsch und die Schweiz als Paten im Vordergrund. Frankreich, so fuhr Kächele fort, werde von Grenzen profitieren, die für immer "gegen Preussen gesichert" wären ${ }^{217}$. "Wir Südwestdeutsche [sind] keine Preussen und wollen mit diesen auch nichts zu tun haben"; damit verdeutlichte Kächele seine antipreußische Haltung. Die Adjektive „neutral“ und „frei“, mit denen Kächele den Staat "Südwestdeutschland“ konnotierte, lassen den Schluß zu, daß eine weitere autonomistische Position vertreten wurde. Die Resonanz des Planes in der Bevölkerung ist aufgrund der wenigen Quellen nicht zu bestimmen.

\footnotetext{
${ }^{216}$ Friedrich Kächele: Die Bildung eines freien Staates „Südwestdeutschland“ (masch. 9 S.) [1945/ 46]; AdO HCFA AP Dir. de l'Int. c. 228 p. 21 d. 72.

217 Ebenda, S. 1.
} 


\section{Die „Europäische föderative Union" - der südwestdeutsche Ableger der Paneuropabewegung}

Bernhard Dietrich ${ }^{218}$, der Bürgermeister von Singen am Hohentwiel, versuchte seine Alpenlandpläne und den „Schwäbisch-Alemannischen Heimatbund“219 in ein abendländisches und zugleich paneuropäisches Gewand zu kleiden, eine Idee, die ihn schon lange beschäftigt hatte. Im Spätsommer 1946 durchdachte er mit seinem Gesinnungsgenossen, dem italienischen Vizekonsul a. D. und Gran Ufficiale Guido Parisch ${ }^{220}$, der seit Juni 1945 in Konstanz wohnhaft war ${ }^{221}$, die Gründung einer politischen Partei, deren unglücklich gewählter Name „Europäische, republikanisch-demokratische-sozial-evolutionistische Partei“ sein sollte. Das ausführliche Lizenzierungsgesuch wurde persönlich beim Konstanzer Bezirksdelegierten Marcel Degliame eingereicht, der es unverzüglich nach Baden-Baden weiterleitete 222 . Doch wenige Tage später änderten Dietrich und $\mathrm{Pa}-$ risch ihre Taktik; im Informationsschreiben an Landeskommissär Nordmann, das identisch mit dem Exposé an die französische Besatzungsmacht war, zogen sie den Antrag auf Parteigründung zurück und zeigten den Wunsch an, einen eingetragenen Verein mit Namen „Europäische föderative Union“ ins Leben rufen zu wollen ${ }^{223}$.

Ein „Zentral-Exekutiv-Komité" war bereits gebildet, der kommissarische Präsident und Leiter der Sektion für Deutschland hieß Bernhard Dietrich, der Generalsekretär und zuständige Mann für Italien war Guido Parisch. Weitere sechs Personen erhielten Funktionen und waren Mitglieder des provisorischen Vorstands ${ }^{224}$. In 25 willkürlich zusammengestellt anmutenden Punkten erläuterte Parisch das Hauptziel der Vereinigung:

${ }^{218} \mathrm{Zu}$ Dietrich vgl. Kapitel III/1.

${ }^{219} \mathrm{Zu}$ den Alpenlandplänen und dem „Schwäbisch-Alemannischen Heimatbund“ vgl. Kapitel III/ 1 und Kapitel III/4.

${ }^{220}$ Guido Parisch (1885-?) (die Kaufmannsfamilie P. war angelsächsischer Abstammung und siedelte sich 1847 in Genua an), italienischer Staatsangehöriger und Freimaurer in der Loge „Alto Adige“ (Südtirol); 1922 verließ der Filmindustrielle P. aus politischen Gründen Italien; Tätigkeit in der Filmbranche in Berlin (Produktion, Synchronisation, Verleih und Vertrieb); 1944 italienischer Vizekonsul in Freiburg i. Br.; Gran Ufficiale; seit 20.6. 1945 wohnhaft in Konstanz.

Zu Recherchen der Kriminalpolizei Konstanz über P. vgl.: Kriminalpolizei Konstanz an Landeskommissär Nordmann vom 7. 10. 1946; StA FR A 96/1 1990 und A 96/1 Spec. 4780.

Nach einem Aufruf von Professor Galosso im Radio Roma am 11. 11. 1945 beantragte Guido Parisch bei Landeskommissär Nordmann die Genehmigung einer Dante-Alighieri Gesellschaft für italienische Kultur und Sprache. Nordmann verwies Parisch am 19. 12. 1945 auf die dafür zuständige Militärregierung; StA FR A 96/1 Spec. 4780.

${ }^{221}$ Als Adresse gab Parisch Huetlinstr. 39 an, also das Gasthaus Metropol; vgl. Stadtadressbuch Konstanz 1943 und 1949.

${ }^{222}$ Das Exposé erreichte das Zivilkabinett von General Koenig am 2. 10. 1946; AdO HCFA Cab. Civil Pol-II-B p. 27.

${ }^{223}$ „Exposé von Guido Parisch in Konstanz hier: Die Bildung der vereinigten Staaten von Europa“; StA FR A 96/1 1990.

${ }^{224}$ Der Direktor der Deutschen Bank - Filiale Konstanz -, Ewald Patschke, zeichnete als Schatzmeister, der Generalsekretär des "Schwäbisch-Alemannischen Heimatbundes“, Leopold Paur, fungierte als juristischer Berater; der Kressbronner Bürgermeister und Regierungsrat a. D. Josef Abrell und Dr. Alfred Rennert waren des weiteren im provisorischen Vorstand. Der Delegierte für die ABZ war der Starnberger Dr. Kurt von Oerthel (ein aus Berlin stammender Filmindustrieller), als Frauenbeauftragte trat Alice Eberlein (eine Jüdin, die von Parisch während des Krieges geschützt worden war) hinzu. Knappes Programm und Liste des Vorstands außerdem in: AdO HCFA Cab. Civil c. 26 POLII-A d. 21. 
die politische Zusammenfassung des Abendlandes durch die Schaffung der Vereinigten Staaten von Europa. Die Vordenker der Ziele seien Victor Hugo, Giuseppe Mazzini und Constantin Frantz gewesen, als Leitfigur und Organisator der Paneuropabewegung erkannte Parisch den Grafen Coudenhove-Kalergi ${ }^{225}$ an. Die „Europäische föderative Union" sah sich nur als Teil einer überall im besetzten Deutschland erstarkenden Paneuropabewegung an ${ }^{226}$. Charakteristisch war für die Paneuropa-Gruppen der Wunsch, unter Umgehung einer deutschen Staatsgründung zuerst eine Europäische Konföderation zu schaffen. $\mathrm{Ob}$ die einzelnen deutschen Länder Mitglieder in einem vereinten Europa werden sollten oder ob zuerst neue autonome Staaten in Deutschland geschaffen werden müßten, darüber gingen die Meinungen auseinander. Die politische Realisierbarkeit der Gedankenspiele war zu keinem Zeitpunkt gegeben, es bleibt aber festzuhalten, daß der Begriff „Abendland“ als Fundament der Vereinigten Staaten von Europa politische Relevanz gewinnen sollte. Für Südwestdeutschland brachten die Paneuropavorstellungen sieht man vom Programm des „Schwäbisch-Alemannischen Heimatbundes“ ab - keine Lösungsvorschläge der durch die Besatzung verfahrenen, territorialen Zustände.

${ }^{225}$ Richard Graf von Coudenhove-Kalergi (1894-1972), 1923 Gründer der Paneuropabewegung; 1938 Emigration in die Schweiz; 1940-46 Historiker an der Universität New York; 1947 Rückkehr in die Schweiz; 1947 Gründer der „Europäischen Parlamentarier Union“; 1950 erster Träger des Karlspreises der Stadt Aachen; 1952 Ehrenpräsident der „Europäischen Bewegung“.

Zu seinen Vorstellungen vgl. Coudenhove-Kalergi, Paneuropa. Ausgehend von der Prämisse, Deutschland sei in seiner Geschichte bis 1871 immer schon ein Staatenbund gewesen, präsentierte Coudenhove-Kalergi im Februar 1948 eine staatenbündische Lösung des deutschen Problems: Die Einteilung in sechs „souveräne“ Staaten. Den südwestlichen deutschen Staat nannte er "Schwaben“ ( ${ }^{\text {Suabia }}$ "), und dieser würde zusammen mit Bayern, dem Rheinland, Niedersachsen, Sachsen und Brandenburg über einen deutschen Staatenbund in eine europäische Föderation integriert; Coudenhove-Kalergi: A German Commonwealth (masch. 3 S.) vom 23. 2. 1948; AdO SGAAA Dir. Pol. c. 10 A12.

${ }^{226}$ Die französische Besatzungsmacht hatte im November 1947 Kenntnis von 24 solcher Bewegungen, deren wichtigste die Europa-Union in Mönchengladbach, die Pan Europa Union in Hamburg, die Europäische Gemeinschaft in Münster, die Europäische Aktion in Stuttgart, die Weltstaat Liga in München und innerhalb der FBZ der "Schwäbisch-Alemannische Heimatbund“, der „Pfälzer Heimatbund“, die Rheinische Volkspartei und die „Autonomen Föderalisten“ (vgl. Kapitel III/4) waren; AdO SGAAA Dir. Pol.c. 43 F12. 